\title{
La buena administración como principio jurídico: una aproximación conceptual
}

Good administration as a legal principle: a conceptual approach

Boa administração como princípio legal: uma abordagem conceitual

Bonne administration en tant que principe juridique: une approche conceptuelle

\section{Andry Matilla Correa ${ }^{1}$ | Universidad de La Habana Cuba}

Revista Derechos en Acción / ISSN 2525-1678 / e-ISSN 2525-1686

Año 4/Nº 10 Verano 2018/2019 (21 diciembre a 21 marzo), 110-160

DOI: https://doi.org/10.24215/25251678e247

ORCID: https://orcid.org/0000-0002-7620-3627

Recibido: $15 / 01 / 2019$

Aprobado: 10/03/2019

Resumen: El principio de buena administración revela un principio de connotaciones genéricas que resulta, en lo formal, una manera de englobar y de dotar de unidad de sentido a determinadas exigencias que debe observar la Administración Pública en su existencia y a ciertos requerimientos y situaciones que se dan en sus relaciones con los ciudadanos 0 administrados. De igual forma, resulta pacífico el punto de partida de que el contenido del principio de buena administración ha quedado reconocido y trazado con un carácter plural y heterogéneo, tanto en las consideraciones de la jurisprudencia y la doctrina, como en la normativa que a él se refiere. Así las cosas, el principio de buena administración se reverla o traduce, según ha tenido oportunidad de dejar en claro su evolución dentro del ámbito jurídico, en un conjunto

1 Doctor en Ciencias Jurídicas. Profesor Titular de Derecho Administrativo de la Facultad de Derecho de la Universidad de La Habana. Presidente de la Sociedad Cubana de Derecho Constitucional y Administrativo de la Unión Nacional de Juristas de Cuba (UNJC). Académico Titular de la Academia de Ciencias de Cuba. 
0 elenco de principios de alcance 0 proyección más particularizados que aquél, así como de derechos (de los ciudadanos o administrados) y deberes (de la Administración Pública) que lo concretan.

Palabras claves: buena administración. Principio jurídico. Administración Pública.

Abstract: The principle of good administration reveals a principle of generic connotations that results, formally, a way of encompassing and providing unity of meaning to certain requirements that must be observed by the Public Administration in its existence and certain requirements and situations that occur in his relations with citizens or administrated. Similarly, the starting point that the content of the principle of good administration has been recognized and mapped with a plural and heterogeneous character, both in the considerations of the jurisprudence and the doctrine, and in the regulations that it contains, is peaceful refers. Thus, the principle of good administration is reviewed or translated, as it has had the opportunity to make clear its evolution within the legal field, in a set or list of principles of scope or projection more particularized than that, as well as of rights (of citizens or administrated) and duties (of the Public Administration) that specify it.

Keywords: Good administration. Legal principle. Public administration.

Resumo: 0 princípio da boa administração revela um princípio de conotações genéricas que resulta, no formal, uma maneira de incluir e fornecer unidade de significado a certos requisitos que a Administração Pública deve observar em sua existência e certos requisitos e situações que ocorrem em suas relações com os cidadãos ou administrados. Da mesma forma, resulta pacífico o ponto de partida de que o conteúdo do princípio da boa administração foi reconhecido e traçado com um caráter plural e heterogêneo, tanto nas considerações da jurisprudência e da doutrina, como nos regulamentos que se refere a ele. Assim, o princípio da boa administração é revelado ou traduzido, como teve a oportunidade de deixar claro sua evolução dentro do campo legal, em um conjunto ou elenco de princípios de escopo ou projeção mais particularizados que aquele, assim como direitos (dos cidadãos ou administrados) e deveres (da Administração Pública) que o materializam.

Palavras-chave: Boa administração. Princípio Legal. Administração pública. 
Résumé: Le principe de bonne administration révèle un principe de connotations génériques qui constitue, de manière formelle, une manière d'englober et de donner une unité de sens à certaines exigences que doit respecter l'administration publique dans son existence et à certaines exigences et situations qui se produisent dans ses relations avec les citoyens ou les administrés. De même, le point de départ selon lequel le contenu du principe de bonne administration a été reconnu et tracé avec un caractère pluriel et hétérogène, à la fois dans les considérations de la jurisprudence et de la doctrine ainsi qu'aux normes auxquelles elle se réfère, est non conflictuel. Ainsi, le principe de bonne administration se montre ou se traduit, selon qu'il ait eu l'occasion de préciser son évolution dans le domaine juridique, dans un ensemble ou une liste de principes de portée ou de projection plus précis que celui-ci, comme des droits (des citoyens ou des administrés) et des devoirs (de l'administration publique) qui le concrétisent.

Mot-clés: Bonne administration. Principe juridique. Administration publique.

“ (...) tout service public demande à être assuré et assuré pour le mieux, car l'Administration, c'est la bonne administration; (...).".

Comentario al affaire Gaz de Deville-lès-Rouen del Consejo de Estado, 10 de enero de 1902,

Maurice Hauriou

\section{Ideas iniciales}

La preocupación por la buena administración en el campo jurídico, no es ni por mucho, algo que nace en el siglo XX o en lo que va del XXI; sino que hunde sus raíces, como la preocupación misma para el buen ejercicio del poder público, en tiempos anteriores.

En viejo libro, entre las tempranas obras generales españolas del siglo XIX sobre Derecho Administrativo, se puede leer en las primeras líneas del mismo: 
“(...) Exponer la utilidad que la sociedad reporta de una buena administración, que reúne en sí los medios necesarios para dar fuerza al gobierno, proteger a los ciudadanos y fomentar los intereses generales del país, sería querer demostrar una verdad que está al alcance de todos, y de que nunca ha dudado ningún hombre sensato sea cualquiera la opinión a que pertenezca. (...).”. ${ }^{2}$

Sin embargo, es en los siglos XX y XXI que la buena administración ha de adquirir, en lo jurídico, dimensiones superiores y definitivas, asumiendo un valor de uso que posiciona y sustenta hoy su funcionalidad trascendental para el marco de ordenación jurídica de la Administración Pública y, con esto, para un importante segmento de las relaciones entre el poder público - organizado y funcional - y los ciudadanos o administrados. Ha sido tal la relevancia que ha ido cobrando la idea de buena administración, que una voz autorizada en estas cuestiones llamaba, justo en las postrimeras de la centuria anterior y el nacimiento de una nueva, a hacer del siglo XXI el "siglo de la buena administración». ${ }^{3}$

Alumbrada y sustanciada, principalmente, en la cultura política, administrativa y jurídica de la Europa occidental, la buena administración ha evolucionado de una consideración jurídica como principio (de organización y funcionamiento de la Administración Pública) y como deber (en cabeza del aparato administrativo público), a una dimensión más ambiciosa como la que ha ganado con el artículo 41 de la Carta de los Derechos

2 García Goyena, Florencio y AguirRe, Joaquín, Febrero o Librería de Jueces, Abogados y Escribanos, comprensiva de los códigos civil, criminal y administrativo, tanto en la parte teórica como en la práctica, con arreglo en todo a la legislación hoy vigente, corregida y aumentada por don Joaquín AguirRe y don Juan Manuel Montalbán, $4^{\text {ta }}$ edición reformada y considerablemente aumentada por don José de Vicente y Caravantes, Tomo IV, Derecho Administrativo, Imprenta y librería de Gaspar y Roig, editores, Madrid, 1852, p. 5.

3 Söderman, Jacob, "Speech of the European Ombudsman -Public Hearing on the draft Charter of Fundamental Rights of the European Union, Preliminary remarks", pronunciado en Bruselas, Bélgica, el 2 de febrero de 2000, disponible en www.ombudsman.europa.eu/ es/activities/speech.faces. 
Fundamentales de la Unión Europea (proclamada en Niza en diciembre de 2000), el cual refrendó un novedoso «derecho a la buena administración» en los siguientes términos:

" 1 . Toda persona tiene derecho a que las instituciones y órganos de la Unión traten sus asuntos imparcial y equitativamente y dentro de un plazo razonable.

2. Este derecho incluye en particular:

- el derecho de toda persona a ser oída antes de que se tome en contra suya una medida individual que le afecte desfavorablemente,

- el derecho de toda persona a acceder al expediente que le afecte, dentro del respeto de los intereses legítimos de la confidencialidad y del secreto profesional y comercial, - la obligación que incumbe a la administración de motivar sus decisiones.

3. Toda persona tiene derecho a la reparación por la Comunidad de los daños causados por sus instituciones o sus agentes en el ejercicio de sus funciones, de conformidad con los principios generales comunes a los Derechos de los Estados miembros.

4. Toda persona podrá dirigirse a las instituciones de la Unión en una de las lenguas de los Tratados y deberá recibir una contestación en esa misma lengua.”. ${ }^{4}$

La consagración allí de ese novedoso derecho, etiquetado como "fundamental» por la propia Carta de Niza, de los ciudadanos frente al funcionamiento administrativo público, no ha sido fortuita, en tanto ello ha respondido a un contexto

\footnotetext{
4 Sigue luego un artículo 42, relativo al derecho de acceso a los documentos, estrechamente vinculado con el 41, y en el que se expresa: “Todo ciudadano de la Unión o toda persona física o jurídica que resida o tenga su domicilio social en un Estado miembro tiene derecho a acceder a los documentos del Parlamento Europeo, del Consejo y de la Comisión.". Por su parte, el artículo 43 de esa misma Carta, a propósito del Defensor del Pueblo, se regula: “Todo ciudadano de la Unión o toda persona física o jurídica que resida o tenga su domicilio social en un Estado miembro tiene derecho a someter al Defensor del Pueblo de la Unión los casos de mala administración en la acción de las instituciones u órganos comunitarios, con exclusión del Tribunal de Justicia y del Tribunal de Primera Instancia en el ejercicio de sus funciones jurisdiccionales.".
} 
que ha venido favoreciendo y potenciando con intensidad - especialmente luego de la II Guerra Mundial - los derechos de los ciudadanos (administrados en general, más allá de las bondades de uno u otro término) frente a los mecanismos y las actuaciones del poder público. ${ }^{5}$ Así las cosas, la aparición del derecho fundamental a la buena administración, y el trazado y nominación como tal derecho, ha de entenderse como una consecuencia del "tiempos de los derechos" (apelando al nombre de una conocida obra de BoвBIo $^{6}$ ), del «lenguaje de los derechos" (en expresión que ya usaba, por ejemplo, Dworkin ${ }^{7}$ ) o de la "lengua de los derechos" (evocando el título de un conocido libro de García DE ENTERRÍA ${ }^{8}$ ), tal y como se han proyectado, especialmente, en Europa occidental desde el segundo lustro de la década de 1940 hasta hoy.

Adquiridos esos ribetes jurídicos, la buena administración no ha quedado ahí, sino que ha trascendido las fronteras europeas para recalar en el marco latinoamericano a través de la Carta Iberoamericana de los Derechos y Deberes del Ciudadano en Relación con la Administración Pública, aprobada por el Consejo Directivo del Centro Latinoamericano de Administración para el Desarrollo (CLAD) en reunión presencial-virtual celebrada desde Caracas el 10 de octubre de 2013, en cumplimiento del mandato recibido por la XV Conferencia Iberoamericana de Ministras y Ministros de Administración Pública y Reforma del

5 Decía el Lorenzo Martín-Retortillo Baquer que, el «derecho a la buena administración» "(...) es ya una llamada genérica a todos los responsables de la diversas Administraciones Públicas, instados a alcanzar el canon que el precepto significa.". Martín-Retortillo Baquer, Lorenzo, "De los derechos humanos al derecho a una buena administración”, en ÁviLa Rodríguez, Carmen María y GutiérRez Rodríguez, Francisco (coordinadores), El derecho a una buena administración y ética pública, Fundación General de la Universidad de Málaga, Málaga.es diputación, Defensor del ciudadano/a, Tirant lo Blanch, Valencia, 2011, p. 50.

6 BobBio, Norberto, El tiempo de los derechos, Traducción de Rafael de Asís Roıg, Editorial Sistema, Fundación Sistema, Madrid, 1991.

7 Dworkin, Ronald, Los derechos en serio, Traducción de Marta Gustavino, Editorial Ariel, S.A., Barcelona, 1984, p. 276.

8 García de Enterría, Eduardo, La lengua de los derechos. La formación del Derecho Público europeo tras la Revolución Francesa, Alianza Editorial, S.A., Madrid, 1994. 
Estado celebrada en Ciudad de Panamá los días 27 y 28 de junio de 2013. Este documento proyecta, sintetiza y desarrolla a la buena administración pública y sus implicaciones, en razón de la triple funcionalidad que se le ha podido dar a la misma: como principio, como deber y como derecho.

Visto así el panorama, puede entenderse perfectamente cómo la idea jurídica de buena administración, en las últimas décadas, se ha ido consolidando y sustanciando al compás de la globalización, pero se ha globalizado o «extendido a nivel global» ella misma.

En definitiva, la cuestión jurídica de la buena administración no involucra sino preocupación por la calidad en la organización y en el funcionamiento administrativos. Pretendiendo ser motor de impulso y medida también de la búsqueda de esos estándares de calidad en la actuación, de los procederes (de ahí la relevancia del tema para el procedimiento administrativo) de la Administración Pública, para el cumplimiento pleno y cabal de los fines administrativos.

La buena administración hace a la naturaleza o esencia misma de todo el fenómeno administrativo público. Por ende, no puede concebirse ese fenómeno, es decir, la Administración Pública en sus diversas aristas, si no es desde la consideración de la cualidad que le imprime la idea de buena y desde lograr en ella - inexcusablemente - lo bueno, lo bien hecho, en sus proyecciones estructurales y funcionales, en su materialización y realización. Por lo tanto, no hay manera de entender a la Administración Pública (subjetiva y objetivamente considerada) si esta no es la buena administración, simplemente porque la mala administración es administración desnaturalizada y, en consecuencia, no puede decirse que es propiamente

\footnotetext{
9 En palabras de CASSESE, Sabino, "II diritto alla buona amministrazione", p. 9, ponencia presentada a la "Jornada sobre el derecho a la buena administración», por el 25 aniversario de la ley del "Síndic de Greuges" de Cataluña, Barcelona, 27 de marzo de 2009, disponible en www.irpa.eu/wp-content/uploads/2011/05/Diritto-alla-buona-amministrazione-barcellona27-marzo.pdf.,
} 
administración, en tanto no conduce al cumplimiento cabal de los fines para los cuales existen el aparato y el espacio funcional administrativos.

En esta cuerda de análisis, se ha llegado a decir que la buena administración significa «el intento de dotar de alma a la Administración Pública ${ }^{10}$ o que ella "es el alma de la nueva administración». ${ }^{11}$

En una clave esencial de ese tipo radica el punto de mira básico del fenómeno de la buena administración desde el Derecho. Claro está, esto como producto de nuevos tiempos, de búsqueda de mejores dinámicas administrativas, de mayores exigencias de los ciudadanos frente a los poderes públicos organizados. La buena administración conecta directamente con, y resume, los nuevos valores con los que se ha querido dotar en las últimas décadas al sistema administrativo público, y de las exigencias de ordenación jurídica de ese sistema y su funcionamiento, buscando rectamente la plena realización de los intereses generales; teniendo, además, como premisa, la reevaluación de la posición del ciudadano o administrado frente a la Administración Pública, el cual pasa ahora a tenerse como «el corazón de la relación jurídica-administrativa» ${ }^{12}$ o, lo que es lo mismo, a considerarse su "centralidad" ${ }^{13}$ en la vida administrativa pública.

10 Tornos Mas, Joaquín, “El principio de buena administración o el intento de dotar de alma a la Administración Pública", en Marín ReBollo, Luis (Director), Derechos fundamentales y otros estudios en homenaje al prof. Dr. Lorenzo Martín-Retortillo, Volumen I, El Justicia de Aragón, Zaragoza, 2008, pp. 629 y sigs.

11 Tornos MAs, Joaquín, "El principio de buena administración...", ob. cit., p. 630.

12 A comienzos de este siglo XX, Jacques Chevaluier advertía que: "Depuis la dernière décennie, les choses ont évolué: la figure du citoyen es désormais présente au cœur de la relation administrative, comme l'attestent les "chartes du citoyen" adoptées dans un certain nombre de pays européens (...).". Chevallier, Jacques, "Préface", en Spanou, Calliope, Citoyens et administration, L'Harmattan, Paris, 2003, p. 7.

13 Como se ha ocupado de enseñar el español Jaime Rodríguez-Arana Muñoz, en no pocos trabajos al efecto: "La buena administración, el buen gobierno, aspira a colocar en el centro del sistema a la persona y sus derechos fundamentales.". Rodríguez-Arana Muñoz, Jaime, 
En los tiempos que corren para el Derecho, el prisma que ofrece pensar el espacio público y sus implicaciones desde el lado que revela la buena administración, no pone solo sobre el tablero un deseo de vida que deriva de la existencia misma del poder público organizado y operante, sino una necesidad cada vez más impostergable para que ese poder cumpla con la condición de factor para la realización de la condición humana.

Y es que -más allá de las experiencias históricas que por miles de años pueden hacer parecer ingenuo este planteamiento-, el poder público no ha de ser un fin en sí mismo, sino medio o instrumento para proveer a la convivencia social del grupo humano y del ser humano como individuo, bajo ciertas condicionantes o aspiraciones de vida que son las que determinan su uso como medio o instrumento y permiten medir la validez y efectividad de esa utilización. De tal suerte, es el poder público un factor de garantía existencial de la sociedad humana y del hombre como individuo, que con el transitar de la marcha vital de la humanidad por los varios milenios que conforman su historia, ha ido pasando de simple medio de dominación, sin más, de unos hombres sobre otros, a hacer del desarrollo a plenitud de la condición humana el aliento vital de su planteamiento y operatividad - al menos en un plano ideal -; sin olvidar que sigue siendo también medio de dominación social.

Por lo hasta aquí dicho, es difícil no derivar entonces en la convicción de que el poder público ha de verse como un mecanismo al servicio de la sociedad y de los integrantes de ella y no como la vía para servirse de la sociedad y de sus integrantes. Un

\footnotetext{
El Buen Gobierno y la Buena Administración de Instituciones Públicas, Thomson-Aranzadi, Editorial Aranzadi, Cizur Menor (Navarra), 2006, p. 34. En otro momento, este profesor acotaba: "La consideración central del ciudadano en las modernas construcciones del Derecho Administrativo y la Administración pública proporciona, en efecto, el argumento medular para comprender en su cabal sentido este nuevo derecho fundamental a la buena administración. (...).". Rodríguez-Arana Muñoz, Jaime, "El derecho fundamental al buen gobierno y a la buena administración de instituciones públicas", en Rodríguez-Arana Muñoz, Jaime y García Mexía, Pablo (Directores) y Mallaina García, Carmela (Coordinadora), El derecho a una buena administración pública, Escuela de Administración Pública de Castilla y León, Junta de Castilla y León, Valladolid, 2008, p. 13.
} 
medio para servir con utilidad el hombre en su travesía social, debe ser el animus que anide en las esencias de ese poder y en cada una de las zonas funcionales, de las piezas estructurales y de los instrumentos en los que se exprese y manifieste. Y con esa perspectiva servicial es que deben encararse todas las acciones de transformación y perfeccionamiento de los resortes del poder público, en los diversos planos y maneras en los que este se proyecta objetivamente.

Ahora bien, la buena administración resulta una noción jurídica indeterminada, de contenido complejo, plural, diverso, abierto, presto a ensanchar sus límites hacia nuevos espacios que consoliden los estándares que la misma puede significar. Vista así, es ella una noción genérica, de síntesis de determinados principios, deberes y derechos en concreto, que a su vez puede ser concretada formalmente en ellos.

En la construcción que se le ha dado por la doctrina, la jurisprudencia y la normativa jurídica - la práctica en general -, la buena administración en su ángulo principal o el principio de buena administración es fórmula que engloba, a la vez que se manifiesta, en una serie de principios que se reconocen hoy como que hacen al fundamento del régimen jurídico de la Administración Pública y, en especial aunque no en exclusiva, al de sus relaciones con los ciudadanos o administrados. Estos principios, con identidad y entidad propia, resultan así principios de buena administración y entre ellos pueden mencionarse, entre los más recurridos y sin ánimo de agotarlos, los de: eficacia, eficiencia, objetividad, economía o economicidad y celeridad, imparcialidad, proporcionalidad, publicidad, transparencia, participación, coherencia, racionalidad, de igualdad de trato o no discriminación, de protección de la confianza legítima, de responsabilidad patrimonial.

\section{La noción de buena administración}

La aproximación a una noción jurídica de buena administración no es cuestión sencilla si nos atenemos al proceso mismo 
de juridificación de dicha noción, así como al universo operativo que ha rodeado a la misma, entendido este desde los planos en que ha podido operar como concepto, la configuración jurídico-formal que puede revestir para o en su concreción, las dimensiones de alcance hacía donde puede extenderse, junto a la pluralidad de contenidos que ha de abarcar.

Lo primero que no puede pasarse por alto es el hecho que la idea de buena administración ha sido una noción que ha recalado con definitiva visibilidad en el Derecho Administrativo, o en el Derecho Público, procedente originariamente de la Ciencia de la Administración; esto es, desde el espacio científico que mira a la perspectiva no jurídica del fenómeno administrativo. Esto es algo que ha sido ya anotado por los estudiosos desde antiguo, por lo que baste recordar entonces lo que un viejo autor portugués comentaba:

\section{"(...) descobertos e conbecidos pela ciência administra- tiva os princípios verdadeiros para a boa administração, são postos em prática, pelo direito administrativo, vindo por conseqüência, este a constituir aqueles princípios reduzidos a obra e levados á prática". ${ }^{14}$}

Es, tal vez, en los predios de la buena administración, donde puede apreciarse con mejor claridad una suerte de diálogo fructífero entre la Ciencia de la Administración y el Derecho Administrativo. ${ }^{15} \mathrm{Y}$, en el aludido recalo, la buena administración

\footnotetext{
14 De FreitAs, Justino Antonio, Ensaio sobre as instituções de Direito Administrativo portuguez, por Augusto Guilherme DE SousA, Imprensa da Universidade, Coimbra, 1859, pp. 37.

15 Nikiforos Diamandouros - quien fuera el segundo Defensor del Pueblo Europeo - consideraba que los principios de buena administración poseen una dimensión jurídica, pero también gozan de lo que denomina "vida más allá de la legalidad». En su sentir: "Lo que deseo transmitir con esta frase es que las fuentes de inspiración de los principios (...) - se refiere a los que enumera allí como de buena administración - se sitúan fuera, o de acuerdo con mi expresión, «más allá» de la ley. No deberíamos, por tanto, esperar que todo su contenido se recoja o exprese en textos jurídicos ni en la jurisprudencia de los tribunales.". Para NiKIForos DiAmANDOUROS: "En otras palabras, la buena administración consta de aspectos jurídicos y no jurídicos, por lo que cabe afirmar que, aunque la legalidad es necesaria para la existencia de la buena administración, no es suficiente. Esta noción fundamental lleva a distinguir
} 


\section{ha ido adquiriendo gradualmente su trascendencia jurídica hasta mostrarse tal y como va resultando hoy. Y es que la buena admi- nistración indica, primariamente, la referencia a una situación más objetiva que formal; ${ }^{16}$ alude más a la materialidad de un fenómeno y no sólo a la ordenación formal del mismo.}

Tal como se ha reconocido ya, la noción jurídica de buena administración trae causa del Derecho europeo, ${ }^{17}$ desde donde

dentro de la mala administración el "incumplimiento de los principios de buena administración" como una categoría aparte de la "no actuación de acuerdo con las normas y principios jurídicos".". Ver al respecto, de Nikiforos Diamandouros, P., "Legality and good administration: is there a difference?", Speech by the European Ombudsman, P. Nikiforos Diamandouros, at the Sixth Seminar of National Ombudsmen of EU Member States and Candidate Countries on 'Rethinking Good Administration in the European Union', Strasbourg, France, 15 October 2007, disponible en http://www.ombudsman.europa.eu/es/activities/speech.faces/en/370/ html.bookmark; y "Buena administración, Estado de Derecho y ética: aspectos esenciales de la calidad de la democracia", presentación en la Facultad de Derecho de la Universidad Autónoma de Madrid, 21 de marzo de 2013, disponible en: http://www.ombudsman.europa. eu/en/activities/speech.faces/en/50715/html.bookmark.

16 Según consideraba González NavarRo: "Para poner un poco de orden en esta materia sería bueno empezar separando los que, de manera provisional y sin compromiso mayor, podemos llamar "principios jurídicos» de aquellos otros que deberíamos llamar "principios de buena administración» [una expresión suficientemente identificadora y que, además, tiene tradición en nuestro derecho positivo, ya que viene empleándose en la legislación de contratos públicos desde la LCE de 1965 (art. 1 0), por lo menos, hasta la LCAP de 16 de julio de 2000 (art. 4)]."; agregando inmediatamente: "Cuando para dar título a mi trabajo he utilizado la rúbrica (principios del buen hacer administrativo) lo he hecho con la intención de designar con una fórmula común lo que en definitiva son dos elementos de un mismo sistema. Hay, en efecto, un quehacer jurídico y un quehacer que podríamos llamar -con bastante precisión- quehacer empresarial de las Administraciones públicas. Uno y otro han de realizarse bien, conforme a reglas determinadas, jurídicas las unas, de dirección de personas y de gestión de medios, las otras.". González Navarro, Francisco, "De los principios del buen hacer administrativo”, en Rodríguez-Arana Muñoz, Jaime y del Guayo Castiella, Î̃̃igo (Dirección), Panorama de las Administraciones Públicas en el siglo XXI. Homenaje al Profesor Eduardo Roca Roca, Boletín Oficial del Estado, Instituto Nacional de Administración Pública, Madrid, 2002, p. 581.

17 Según Carrillo DonalRE: "Anclado en la tradición jurídica de ciertos Estado europeos, la buena administración es, sin lugar a dudas, una noción forjada al calor del Derecho comunitario europeo. No obstante, el concepto de buena administración no ha tenido plasmación explícita en los Tratados ni en el Derecho comunitario derivado hasta hace relativamente poco tiempo. (......". Carrillo DonalRe, Juan Antonio, "Buena administración, ¿un principio, un mandato o un derecho subjetivo?", en Santamaría Pastor, Juan Alfonso (Director), Los principios jurídicos del Derecho Administrativo, La Ley, Wolters Kluwer España, S.A., Madrid, 2010, pp. 1139 y 1140. 
se ha ido irradiando su uso hacia otras latitudes. A lo que puede agregarse que ha sido también resultado y expresión de la cultura iuspública europea, especialmente.

El uso de las expresiones mala administración y buena administración (una y otra han tenido importancia para asentar lo que se ha logrado hasta hoy - en la teoría y en la práctica - en sede de buena administración) no constituye patrimonio exclusivo de los documentos y de los iuspublicistas de la segunda mitad siglo XX y lo que va del XXI. Por el contrario, en escritos de Derecho Público y Derecho Administrativo del siglo XIX y los primeros lustros del XX, ya es posible encontrar la presencia de tales locuciones; incluso, antes del período decimonónico puede hallarse traza de esa existencia. ${ }^{18}$

Un repaso con cierto detenimiento por la bibliografía decimonónica producida en Francia, ${ }^{19}$ España $^{20}$, en algún otro país

18 Muy poco antes de la irrupción de la Revolución francesa (1789) en la escena histórica, un autor, Louis-Henri DuCHESNE DE VoIRONS, daba a la luz (al parecer alrededor de 1788) un breve opúsculo titulado Premiers Principes d'une bonne administration causes de la décadence d'un royaume. No era esa una obra de contenido propiamente jurídico, pero bien nos puede servir para ilustrar como las preocupaciones por proyectar una bonne administration en el ámbito público no es algo que aparece cercan a nosotros en el tiempo, sino que, salvando las distancias y los contextos históricos, y el instrumental categorial teórico-práctico propio de cada tiempo político-jurídico, ya es posible ir viendo que tanto la denominación (bonne administration), como la idea de su importancia para la vida pública de una comunidad políticamente organizada, estaban presentes en las inquietudes - y en la literatura generada a partir de esas inquietudes - de quienes, de alguna manera, pensaban sobre las necesidades de esa comunidad para encausarla según los derroteros socio-políticos de momentos premodernos - al menos en el pasado inmediatamente más cercano a la modernidad -. Ciertamente, buena administración (bonne administration) no es un concepto jurídicamente trascedente en aquellos tiempos, pero tampoco una expresión genéricamente irrelevante cuando era utilizada, en tanto la "grandeza o decadencia (buena marcha) del reino" se conectaba a su "buena administración"; tal como podemos derivar del título del opúsculo de DucheSNE DE VoIRONS mencionado como ejemplo. Es en el siglo XIX que poco a poco, de forma imperceptible quizás, van dándose mayores asociaciones de la buena administración, como idea, con el mundo jurídico que marca la existencia de la Administración Pública y su proyección y relaciones con la comunidad y los individuos. De tal suerte, comenzaban a darse, sin conciencia al respecto, los pasos iniciales de lo que en la centuria posterior iría emergiendo como un concepto jurídicamente relevante, y que en el siglo XXI cristalizaría como tal en el Derecho europeo.

19 Entre todos los iuspublisicas franceses decimonónicos, es, quizás, Édouard LaferRière quien menciona más veces a la bonne administration, en su precursor tratado sobre el contencioso- 
europeo $^{21}$, o hasta aquella facturada en el perímetro de la América Latina ${ }^{22}$ - que en esto es un área del pensamiento mucho menos conocida, incluso para los propios - nos puede revelar el uso de la expresión buena administración por los doctrinantes de esa época; e incluso su presencia en el texto de alguna norma de carácter legal o reglamentario; ${ }^{23}$ o en el de alguna jurisprudencia.

administrativo. En LaferRIÈRE, como en otros autores de la época, está presente la idea de bonne administration, y así lo proyecta con el uso que hace de ella en la obra de referencia, como elemento informador, determinante, como criterio de adecuación, como medida y como finalidad de la actuación de la Administración Pública en diversas esferas y ligada también a la actuación jurisdiccional del Consejo de Estado. Incluso, en algún momento habla de devoir de bonne administration en materia de recursos financieros o económicos de la Administración. En un interesante fragmento, con un sabor de actualidad, LafERRIÈre escribió: “ (...) les formes imposées à un acte administratif ne le sont pas dans l'intérêt distinct de telle ou telle partie, mais dans l'intérêt de l'acte administratif lui-même, de sa correction, de sa maturité, en un mot dans un but de bonne administration. (....).". Ver: LAFERRIÈRE, Édouard, Traité de la juridiction administrative et des recours contentieux, Tome I y II, Deuxième édition, Berger-Levrault et Cie, Libraires -Éditeurs, Paris, 1896, especialmente del tomo I pp. 6, 102, 271, 441, 546 y del tomo II pp. 138, 207, 245, 280, 560, 622. El fragmento transcrito corresponde al Tom II, p. 522 y 523.

20 Es, tal vez, en la obra de José de PosAda de HerRera, Lecciones de Administración, otro de las primeros grandes textos del iusadministrativismo ibérico, donde haya mayor utilización de la expresión buena administración, dentro de la primera literatura española de Derecho Administrativo del período decimonónico. En verdad, la voz buena administración aparece empleada en numerosas ocasiones por este maestro español, a lo largo de sus clásicas Lecciones de Administración, v. gr.: de Posada Herrera, José, Lecciones de Administración, del Sr. D. José de Posada de Herrera, Catedrático de esta ciencia en la Escuela especial de Madrid, trasladas por sus discípulos D. Juan Antonio de Bascón, D. Francisco de Paula Madrazo, y D. Juan Pérez CAlBo, $2^{\text {da }}$ edición, Colección clásicos de la Administración, Instituto Nacional de Administración Pública, Madrid, 1988, pp. 60, 79, 113, 117, 128, 159, 171, 172, 184, 191 , 193, 330, 353, 377, 439, 459, 503, 592, 733.

21 Por ejemplo: De Freitas, Justino Antonio, ob. cit., pp. 37, 43, 148 y 298; De Fooz, J.-H.N., Le droit administratif belge, Tome I, De l'organisation et de la compétence des autorités administratives, H. Casterman, Éditeur, Paris, Tournai, 1859, p. 206; Scoları, Saverio, Del Diritto Amministrativo, Edizione corretta ed accresciuta, Presso i Fratelli Nistri, Pisa, 1856, pp. 9, 10 , 13,234 y 240.

22 Como ilustración, pueden verse las interesantes reflexiones del argentino: FerreYra, Ramón, Derecho Administrativo General y Argentino, Imprenta de Pablo E. Coni, Buenos Aires, 1866, pp. 15 a 18.

23 Recordemos que ya en el Real Decreto disponiendo los Subdelegados y demás empleados de Fomento que había de haber en las provincias españolas, en el Capítulo VI, "Policía 
En ese repaso, nos podemos dar cuenta que si bien buena administración no es una voz que abunda en las páginas de esos textos, tampoco resulta infrecuente encontrarla diseminada o esparcida por aquellas páginas en uso ocasional, asistémico, ya con un alcance común o más llano, ya con ciertas implicaciones o sentido jurídico realmente poco explicitado y sin precisiones apreciables sobre sus consecuencias, como en las centurias posteriores se le ha ido asignando gradualmente como noción jurídica. Aún así, primitivamente configurado, la evocación de esa locución no deja de traslucir ese matiz jurídico; incluso en ocasiones utilizándose expresiones bien cercanas a nosotros hoy como los principios de una buena administración ${ }^{24}$ o principios de buena administración, ${ }^{25}$ o reglas de una buena administración, ${ }^{26}$

general”, se podía leer en el artículo 34: “34. S. M. la REINA Gobernadora quiere que ninguna prevención especial se haga en esta Instrucción relativa a la alta Policía. S. M. se lisonjea de que generalizados los beneficios que una Administración paternal debe producir, no habrá maquinaciones contra el reposo de los pueblos, ni por consiguiente necesidad de otras medidas de policía que las puramente administrativas, dulces y protectoras, como deben ser siempre todas las que emanan de una buena Administración.". En la letra de ese Real Decreto mencionado, de 30 de noviembre de 1833, estaba la mano de uno de los grandes precursores de la modernización de la Administración española del siglo XIX: Javier de Burgos. Ver la reproducción de ese Real Decreto como apéndice en: Mesa Segura, Antonio, Labor administrativa de Javier de Burgos, Publicaciones del Instituto de Estudios de Administración Local, C. Bermejo, Impresor, Madrid, 1946, p. 178.

24 Proudhon, Traité du domaine public ou de la distinction des biens considérés principalement par rapport au domaine public, Tome III, Chez Victor Lagier, Librairie-Éditeur, Dijon, 1834, p. 303; Gaudry, Traité du domaine. Comprenant le domaine public, le domaine de l'État, le domaine de la couronne, le domaine privé des communes, le domaine départemental suivi d'un appendice, Tome I, Auguste Durant, Libraire, Paris, 1862, p. 269; Cruet, Jean, Étude juridique de l'arbitraire Gouvernemental et Administratif. Des cas où l'autorité gouvernementale et administrative n'est pas tenue, sous des sanctions efficaces, de respecter les droits individuels et la légalité, Librairie Nouvelle de Droit et de Jurisprudence, Arthur Rousseau, Editeur, Paris, 1906, p. 355.

25 JacQuelin, René, Les principes dominants du contentieux administratif, V. Giard et E. Brière, Libraires, Éditeurs, Paris, 1899, p. 257

26 Véase, por ejemplo: Foucart, E.-V., Eléments Foucart, E.-V., Eléments de Droit Public et Administratif, ou-exposition méthodique des principes du Droit Public positif précédés de la Constitution du 14 janvier 1832 et des senatus-consultes des 7 novembre et 25 d'décembre 
o formas de una buena administración, ${ }^{27}$ o deberes o deber de buena administración. ${ }^{28}$.

Constatado en ello el uso de una locución como buena administración (mala administración) en la etapa decimonónica, tanto en un sentido más corriente, como en otro más propio de lo jurídico, tal vez no pecamos de desatinados si asumimos que, entre los publicistas y los administrativistas del siglo XIX y los primeros momentos del XX, buena administración (y mala administración) resultaba el etiquetado de una idea establecida pero no esclarecida, una suerte de sentimiento jurídico que anidaba en el universo iusadministrativo, pero sin acompañarse de una construcción jurídica que la identificara y la llenara, de manera más precisa, de contenido y consecuencias en el plano de la ordenación jurídica de la Administración Pública. ${ }^{29}$ La idea de buena administración en ese contexto, no debe entenderse,

1853, Tome II, quatrième édition, A Marescq et E. Dujardin, Libraire -Éditeurs, Paris, 1855, p. 729; Foucart, E.-V., Eléments de Droit Public et Administratif, ou-exposition méthodique des principes du Droit Public positif précédés de la Constitution du 14 janvier 1832 et des sénatus-consultes des 7 novembre et 25 d'décembre 1853, Tome III, quatrième édition, A Marescq et E. Dujardin, Libraire -Éditeurs, Paris, 1856, p. 311; Perriouet, E., Les contrats de I'État, Imprimerie et Librairie Générale de Jurisprudence Marchal, Billart et Cz, Imprimeurs Éditeurs, Paris, 1884, p. 252.

27 Strauss, Albert, Des autorités investies de attributions de police, Thèses pour le doctorat, Henri Jouve, Imprimeur, Paris, 1898, p. 21

28 Gaudry, ob. cit., p. 367; Laferrière, Édouard, Traité..., Tome II, ob. cit., p. 245.

29 El profesor español Martín BAssols Coma, hubo de observar hace ya algún tiempo que: "Hasta el momento en que Hauriou elevó el concepto de "Bonne administration» a la categoría de estándar o directiva, aquel mantenía en el lenguaje jurídico una significación difusa y simbólica, equivalente a una descripción del buen orden de la acción administrativa en su ejercicio y oportunidad. $Y$ en tal sentido puede equipararse perfectamente a conceptos como bien común, interés público, regularidad de las operaciones y actos administrativos. Su invocación y funcionalidad ideológica estuvo presente, no obstante, en las primeras etapas del régimen administrativo y en especial en la configuración primitiva de la jurisdicción contencioso-administrativa: la tensión entre las facultades jurisdiccionales propiamente administrativas del Juez administrativo. (...).". Bassols Coma, Martín: "El principio de buena administración y la función fiscalizadora del Tribunal de Cuentas", en AA.VV., El Tribunal de Cuentas en España, Volumen I, Dirección General de lo contencioso del Estado, Instituto de Estudios Fiscales, Madrid, 1982, p. 265. 
jurídicamente hablando, con las mismas connotaciones que ha ido adquiriendo y se le han ido precisando, a la luz de la sustanciación que se le ha dado a partir de la segunda mitad del siglo XX y lo que va del XXI, en especial en las consagraciones positivas que ha tenido.

No nos cabe dudas de que ha de encontrarse una gran riqueza y diversidad cuando se trata de indagar sobre los antecedentes de la presencia o aplicación de la noción de buena administración (y de mala administración) en el campo jurídico, especialmente en lo que hace al panorama del Derecho Público europeo del siglo XIX y principios del XX. Una riqueza y diversidad que apunta a reforzarnos el sentimiento de que, tal como se ha ido proyectando el tema de la buena administración dentro del contexto jurídico actual, es un tópico cuya presencia no es algo que se haya descubierto del todo ahora, ni su enarbolación e identificación como principio resulta de los días actuales, ${ }^{30} \mathrm{ni}$ siquiera la denominación de buena administración es nueva. ${ }^{31}$

Creemos que es válido sostener que en el espacio del siglo XIX está el germen primario, el estadio más primitivo, de la construcción de lo que va resultando hoy el régimen jurídico de la buena administración, entendida esta como principio de la Administración pública, como deber de ella, o como derecho

\footnotetext{
30 Joaquín Tornos Mas es de los que ha considerado que la buena administración se nos presenta como un nuevo principio rector de la actuación de las administraciones públicas; o como un principio de reciente creación. Ver: ToRnos MAS, Joaquín, El derecho a una buena administración, Sindicatura de Greuges de Barcelona, Barcelona, 2007, pp. 14 y 17, disponible en http://www.sindicadegreugesbcn.cat/pdf/monografics/administracio_es.pdf،

31 Desde la perspectiva actual, y a la luz del Derecho de la Unión Europea (artículo Carta de Niza de 2000), quizás la novedad está en la denominación de derecho de buena administración o derecho fundamental a la buena administración, es decir, llamarle derecho o articular usa formula nominativa, pero no ciertamente la expresión buena administración, que como iremos viendo más adelante es de vieja data como recurso nominativo con valor de uso dentro del universo iuspúblico. Por ejemplo, para resaltar la línea de quienes ven novedad en el uso de la fórmula buena administración, Miguel Antonio Guevara Quintanilla ha aseverado: "(...) el hablar de buen gobierno o buena administración, nos introduce a terminología novedosa y que implica una serie de compromisos no solo institucionales sino personales. (...)."; Guevara Quintanilla, Miguel Antonio, El derecho a la buena administración, Servicio de Publicaciones, Facultad de Derecho, Universidad Complutense, Madrid, 2010, p. 41.
} 
atribuido a los ciudadanos o administrados, según se maneja en el actual universo jurídico-administrativo.

Lo que se ha hecho, en definitiva, en el contexto jurídico más actual, no es innovar la buena administración, sino dotarla de definitiva visibilidad y potenciarla, ir confiriéndole paulatinamente configuración y contenido jurídicos; advirtiéndose mejor, delineándose, reforzándose, desplegando las posibles consecuencias que implica en diversos ámbitos de la Administración Pública. En fin, lo que se ha hecho en los últimos lustros es revitalizarla, consolidarla, potenciarla, y otorgarle una nueva dimensión como pilar del orden jurídico administrativo que se desenvuelve por estos días. Pero, todo ello, al igual que cualquier fenómeno jurídico, como resultado de un proceso evolutivo que se ha forjado al calor de la marcha y transformaciones del espacio iuspúblico.

El proceso evolutivo de la juridificación de la noción de buena administración no ha sido sencillo y como todo proceso pueden identificarse en él varios momentos. Ya hemos aludido a una etapa primaria que alcanza el siglo XIX y quizás algo de lo primero de la centuria posterior.

Es con el siglo XX y su avance hacia un nueva etapa, que la noción de buena administración ha de conocer un camino de franco ascenso y tecnificación, jurídicamente hablando, tanto en lo teórico como en lo práctico. Hasta poco más de la primera mitad de esa centuria, la obra escrita del francés Maurice HauRIOU $^{32}$ y la consagración positiva del buon andamento en la letra del artículo 97 de la Constitución de Italia de 1947, ${ }^{33}$ junto a

32 Es en, y a través de, sus memorables comentarios a la jurisprudencia administrativa donde va resaltando en el maestro de Toulouse, de manera expresa, el uso de la idea de la buena administración como noción con consecuencias técnico-jurídicas más precisas; un uso que numéricamente es frecuente en esos comentarios. Ver esos comentarios recogidos en: Hauriou, Maurice, La Jurisprudence Administrative de 1892 à 1929, D'après les notes d'arrêts de Recueil Sirey réunies et classées par André Hauriou, 3 tomos, Librairie du Recueil Sirey (Société Anonyme), Paris, 1929 (Nouveage tirage 1931).

33 El artículo 97 indicado se coloca dentro de la Constitución italiana de 1947 en la Parte II: "Ordinamento della Repubblica"; Título II: "II Governo"; Sección II: "La Pubblica Amministrazione". Y quedó redactado de la siguiente manera: "I1 pubblici uffici sono organizzati 
los análisis de algunos doctrinantes de este último país, que se produjeron antes y unos años después de la entrada en vigencia de esa norma constitucional, ${ }^{34}$ han de tenerse como hitos esenciales e insoslayables en esta nueva etapa que comprendió la marcha de la idea de buena administración en pos de su necesaria juridificación. ${ }^{35}$

Hacia el último cuarto del siglo XX y la primera década del XXI, el tema de la buena administración (o la mala administración) va trascendiendo definitivamente de los ordenamientos jurídicos nacionales que, de un modo u otro, lo reflejaban con cierto cariz jurídico, ${ }^{36}$ para entrar en una nueva e importantísima fase en su construcción jurídica, esta vez de la mano, en especial, de las transformaciones y exigencias que ha de ir imponiendo el proceso de integración europeo. En este período mencionado, se ha de cifrar un momento importante en el

secondo disposizioni di legge, in modo che siano assicurati il buon andamento e l'imparzialità dell'amministrazione.

Nell' ordinamento degli uffici sono determinate le sfere di competenza, le attribuzioni e le responsabilita proprie dei funzionari.

Agli impieghi nelle pubbliche arruninistrazioni si accede mediante con corso salvo i casi stabiliti dalla legge.".

34 V. gr., los importantes trabajos de: RESTA, Rafaelle, "L'onere di buona amministrazione", en AA.VV., Scritti giuridici in onore di Santi Romano, Voume II, Dirito Amministrativo, CEDAM, Casa Editrice Dott. Antonio Milani, Padova, 1940, pp. 105 y sigs.; y Falzone, Guido, I/ dovere di buona amministrazione, Dott. A. Giuffrè Editore, Milano, 1953.

35 No puede olvidarse aquí a la Constitución uruguaya de 1952 que incluía específicamente la expresión buena administración (en la italiana figuraba el buon andamento) en la letra del artículo 311, el cual quedaba comprendido dentro del Capítulo II, Sección XVII “De lo contencioso administrativo", y tenía esta redacción en su primer párrafo: "Cuando el Tribunal de lo Contencioso Administrativo declare la nulidad del acto administrativo impugnado por causar lesión a un derecho subjetivo del demandante, la decisión tendrá efecto únicamente en el proceso en que se dicte."; mientras que en el segundo párrafo de disponía: "Cuando la decisión declare la nulidad del acto en interés de la regla de derecho o de la buena administración, producirá efectos generales y absolutos.".

36 Además de lo que hasta aquí hemos expuesto, véase, entre otros, las referencias que aportaba Ponce Solé, Juli, Deber de buena administración y derecho al procedimiento debido. Las bases constitucionales del procedimiento administrativo y del ejercicio de la discrecionalidad, Lex Nova, S.A., Valladolid, 2001, pp. 142 y 143. 
redondeo, desarrollo y evolución de la buena administración como noción jurídica, donde han desempeñado un rol determinante ciertos instrumentos jurídicos comunitarios europeos que han consagrado jurídicamente a la buena administración, ${ }^{37}$ incluso en la nueva perspectiva de un derecho (artículo 41 de la Carta de Niza de 2000), y no solo desde la percepción de una regla, principio o deber jurídicos; y la jurisprudencia europea. ${ }^{38}$ Esto ha servido, a su vez, como influencia y exigencia de ajustes e interpretaciones para los ordenamientos nacionales que quedan comprendidos dentro del espacio de integración comunitario del «Viejo Continente» - todo eso debe interpretarse dentro de ese proceso de integración -. E, incluso, la trascendencia ha traspasado los límites espaciales de Europa, y ha generado influencia para otros ordenamientos jurídicos

37 Una autora como Susana TavareS da SIIVA considera que: “ 0 princípio da boa administração é originário dos Tratados que instituíram a CEE, não resultando, (...), de uma "criação jurisprudencial".". Tavares da Silva, Susana, Direito Administrativo Europeu, Imprensa da Universidade de Coimbra, Coimbra, 2010, p. 27.

38 Ha dicho Carrillo DonalRe que: "La primera vez que el TJCE aludió expresamente al principio de buena administración fue en su sentencia Industrias Siderúrgicas asociadas c. las Alta Autoridad, de 11 de febrero de 1955 (As. 4/54) donde se pronunció sobre la obligación de motivar las decisiones de la Alta Autoridad como un deber derivado de las reglas de la buena administración. Poco después, el 10 de mayo de 1960, el Tribunal dictó tres sentencias, también en casos relativos a ciertas actuaciones de la Alta Autoridad de la CECA (As. Acum. $3 / 58$ a $18 / 58,19 / 58$ y $27 / 58$ a $28 / 58$, respectivamente), en los que se pronunció sobre la obligación de resolver en un tiempo razonable como una vertiente integrante del derecho a una buena administración.”. CARrillo DonalRe, Juan Antonio, ob. cit., p. 1140, nota 3. También Io apuntaba: YeNG-SENG, Wanda, "Le Médiateur européen, artisan du développement du droit à une bonne administration communautaire", en Rev. trim. dr. h., 58/2004, p. 529, disponible en http://www.rtdh.eu/pdf/2004527.pdf. Tridimas apuntaba que el tribunal europeo ha puesto atención al principio del buen gobierno o buena administración desde 1976, aunque con más sistemáticamente desde la década de los noventa. En su percepción: "Su elevación a un principio general coincide con el crecimiento y el incremento de la diversidad de la Comunidad administrativa, que permite a los tribunales comunitarios elaborar estándares de buen gobierno y responsabilidad.". En su estudio, este autor aporta una perspectiva global del principio de buena administración en el contexto de la jurisprudencia europea, advirtiendo que, de inicio, la jurisprudencia más antigua aludía a que la administración debería ser "adecuada» y «buena», pero la más reciente utiliza el principio de "buena administración». Tridimas, T., The General Principles of EU Law, Oxford University Press, Oxford, 2006, pp. 410 y sigs. 
fuera de ese perímetro geográfico, como es el caso latinoamericano, donde se ha ido recibiendo e incorporando los resultados conceptuales de la evolución jurídica en torno a este tema de la buena administración.

Como puede verse, para llegar al sentido que se aprecia hoy en la noción jurídica de buena administración, se ha dado un viaje de ida y vuelta entre ordenamiento nacionales europeos y el Derecho Comunitario de Europa.

Cuando se trata de realizar una aproximación o determinación del concepto de buena administración en lo jurídico, algunos de los autores que se han ocupado del tema en estos tiempos, han advertido que un camino necesario para llegar a él ha de ser su contraposición con la noción de mala administración; ${ }^{39}$ la cual ha tenido igualmente una relevancia jurídica insoslayable (especialmente en el Derecho anglosajón ${ }^{40}$ ) para el ámbito del Derecho Público. ${ }^{41}$

39 Recordaba Jacob Söderman, primer Defensor del Pueblo Europeo, que "Al principio de mi primer mandato, el Parlamento Europeo me pidió que definiera el concepto de "mala administración". (...)."; Söderman, Jacob: "El derecho fundamental a la Buena administración", en Gaceta Jurídica de la Unión Europea y de la competencia, No. 214, 2001, pp. 8 y sigs. (disponible como "El derecho fundamental a la buena administración" - Discurso pronunciado por el Defensor del Pueblo Europeo, Jacob SöDerman - Ciclo de Conferencias: El papel de los Defensores del Pueblo en un mundo en transición, Mallorca, España, 28 de mayo de 2001, en http://www.ombudsman.europa.eu/es/activities/speech.faces/es/296/html.bookmark. La definición de maladmnistration que se propuso por el Ombudsman europeo y que fue aceptada, acogía: "Maladministration occurs when a public body fails to act in accordance with a rule or principle which is binding upon it.". SöDERMAn, Jacob, "Speech of the European Ombudsman...", ob. cit.

40 A tenor de la emergencia de la maladministration con significación técnica o en su utilización como concepto jurídico, específicamente en Gran Bretaña, donde autoridades políticas y autores desempeñaron un papel determinante en esto, un autor precisaba, poco tiempo después de haberse adoptado, en ese país la famosa Parliamentary Comissioner Act de 1967, por la que se creaba un Parliamentary Comissioner for Administration u ombudsman inglés): " "Nobody can define maladministration in plain terms," said Sir Edmund Compton, the first British Parliamentary Commissioner for Administration or Ombudsman. It may be difficult to define, but most of us believe that we could recognize an example of it, if we saw it. We can describe it by examples. We know what it is, but we are quite ready to admit that we might find ourselves in disagreement with other people about whether or not a particular case was an example of maladministration. We would admit also that there might be a vague and uncertain 


\title{
En consideración del alemán Siegfried Magiera:
}

\author{
"Una primera definición de buena administración, se \\ puede obtener diferenciando esta de una deficiente \\ administración. Una administración deficiente se carac- \\ teriza por una violación de las reglas o principios que \\ son vinculantes para la administración. Una buena \\ administración incluye por lo tanto el cumplimiento de \\ todos los requisitos legales y otros mandamientos, tanto \\ en el área interna como externa, de las relaciones con los \\ ciudadanos y otras partes interesadas". ${ }^{42}$
}

boundary surrounding the areas of maladministration. (...).". WHEARE, K. C., Maladministration and its remedies, Stevens \& Sons, London, 1973, p. 6. Como dato al respecto, podemos señalar que en el First Annual Report of the Northern Ireland Commissioner for Complaints, de 1970, parágrafo 20, se decía que la maladministration era una: "(...) administrative action (or inaction) based on or influenced by improper considerations or conduct. Arbitrariness, malice or bias, including discrimination, are examples of improper considerations. Neglect, unjustifiable delay, failure to observe relevant rules and procedures, failure to take relevant considerations into account, failure to establish or review procedures where there is a duty or obligation on a body to do so, are examples of improper conduct.". Citado por: WheARE, K. C., ob. cit., p. 11.

41 Destacaba Marcos Gómez Puente que “(...) el concepto de mala administración aglutina inicialmente un conjunto de conductas administrativas (acciones u omisiones) que aun soportando o eludiendo con éxito el control formal de legalidad propuesto por un sistema de garantías deficiente e inacabado resultan «injustas». Esta alusión al «injusto» que resulta de la doctrina y el derecho positivo ingleses no supone una valoración preconcebida de la Justicia, con connotación iusnaturalista, sino que viene referida al conjunto de principios formales, valores materiales y reglas de buena administración que resultan del Derecho inglés positivo y consuetudinario; lo injusto, en consecuencia, equivale aquí a lo antijurídico.". Más adelante, este autor enseñaba: "(...) La mala administración es, por tanto, un concepto que aglutina una serie de conductas administrativas variopintas, de diferente naturaleza y efectos, cuya validez formal no puede contrastarse adecuadamente a través de causes ordinarios de control de la actividad administrativa, bien porque no sea posible emplazarlas ante las instituciones de control, bien porque la actuación de éstas resulte ineficaz.". Gómez Puente, Marcos, La inactividad de la Administración, $4^{\text {ta }}$ edición, Thomson Reuters (Legal) Limited, Editorial Aranzadi, S.A., Cizur Menor (Navarra), 2011, pp. 64 y 65.

42 Magiera, Siegfried, "El derecho a una buena administración en la Unión Europea", texto traducido por Mario Kolıing, y revisado con la colaboración de María Jesús Montoro, contribución basada en el comentario del autor al art. 41 de la Carta de los Derechos Fundamentales de la UE, en: MeYER, Jürgen, (ed.), Charta der Grundrechte der Europäischen Union, NomosKommentar, Baden- Baden, 3. Edición 2011, pp. 518-528, disponible en http://eapc. gencat.cat/web/.content/home/publicacions/col_leccio_materials/26_les_administracions_en_perspectiva_europea/8_magiera/08-magiera_tradcast.pdf. Carmen María ÁviLA 
Lo mismo puede decirse para la fijación de la mala administración, en relación con la buena administración. ${ }^{43}$ Afirmaciones de este tipo traen causa del propio desarrollo jurídico del universo de la Administración Pública, donde la necesidad de enfrentar, desde antiguo, la mala administración (maladministration, mauvaise administration) ${ }^{44}$ y de proveer a

RodRíGuEZ comentaba que "Hablar de buena administración conlleva preguntarse por lo que sea la mala administración. (... ..", en Ávila Rodríguez, Carmen María, La Tutela Parlamentaria de la buena Administración. Perspectiva Estatal y Autonómica de los Comisionados Parlamentarios, Thomson Reuters, Editorial Aranzadi, S.A., Cizur Menor (Navarra), 2013, p. 168.

43 Carmona y Choussat, por ejemplo, sostenía que en "(...) el problema del significado concreto de lo que sea mala administración. Valga para ello provisionalmente la interpretación (...), como concepto opuesto a la buena administración o administración diligente. (...).". Luego este autor diría que eran "(...) correctas las posiciones que defienden que existe un concepto de "buena administración» definido por la jurisprudencia (...), que podría a sensu contrario identificar un concepto de mala administración". CARmona y Choussat, Juan Francisco, El Defensor del Pueblo Europeo, Instituto Nacional de Administración Pública, Madrid, 2000, pp. 206 y 316. En las palabras de PonCE Solé: "(...) La mala administración puede ser entendida, (...), como el antagónico de la buena administración, el negativo de este concepto, su contrapuesto, que precisamente por serlo, revela, al ponerlo al trasluz, la existencia de ese deber de buena administración (...).". Ponce SolÉ, Juli, ob. cit., p. 134.

44 En importantes escritos de Alexis DE TocouevilLE, en pleno período decimonónico, es factible encontrar la inclusiones de la expresión mala administración en más de un momento; si bien en un sentido común y no propiamente jurídico. Según de ToCoueville: "Les fonctionnaires publics, dit la constitution du Massachusetts, seront condamnés pour la conduite coupable qu'ils auront tenue et pour leur mauvaise administration'. Tous les fonctionnaires qui auront mis I'État en danger, par mauvaise administration, corruption, ou autres délits, dit la constitution de Virginie, pourront être accusés par la chambre des députés."; De Tocoueville, Alexis, De la démocratie en Amérique, Tome premier, Quatorzième édition, Michel Lévy Frères, Librairie Éditeurs, Paris, 1864, en Ouvres complètes d'Alexis de Tocqueville, Tomo I, publiées par Madame de Tocoueville (et Gustave de Beaumont), Tome premier, Imp. Simon Raçon et comp., Paris, 1864, p. 183. En otro momento de esta obra, DE Tocoueville sostuvo: “La mauvaise administration d'un magistrat, sous la démocratie, est d'ailleurs un fait isolé qui n'a d'influence que pendant la courte durée de cette administration. La corruption et l'incapacité ne sont pas des intérêts communs qui puissent lier entre eux les hommes d'une manière permanente.". En otra gran obra, El Antiguo Régimen y la Revolución, DE ToCQuevilLE colocaba el siguiente comentario en la nota correspondiente a la referencia sobre "La decadencia de las ciudades libres en Alemania. Ciudades imperiales": "Internamente se hallan abrumadas por tantas deudas; éstas obedecen, por una parte, a que aún se les continúa imponiendo gravámenes del Imperio, de acuerdo con su antiguo esplendor, y, por la otra, a que están muy mal administradas. Pero lo que resulta más sorprendente es que esta mala administración parece depender de una enfermedad secreta, común a todas ellas, independientemente de su forma 


\section{la buena administración, ${ }^{45}$ han sido puestas de relieve ganando} en intensidad, en conciencia y en búsqueda de soluciones, ora apuntando a un sentido (enfrentar la mala administración), ora apuntado al otro (proveer a la buena administración). ${ }^{46}$

No les falta razón a los autores que así se han pronunciado, si nos atenemos a la conexión que existe entre buena administración y mala administración. Una de las conclusiones que podemos sacar en claro, en relación con todo lo dicho hasta aquí, es que buena administración y mala administración,

de organización, sea ésta aristocrática o democrática, da lugar a quejas si no idénticas, por lo menos igualmente enérgicas; se dice que, aristocrático, el gobierno es camarilla de un reducido número de familias: el favor y los intereses particulares lo pueden todo; democrático, la intriga y la venalidad imperan en todas partes. En ambos casos el ciudadano se queja de falta de honestidad y de desinterés por parte de los gobiernos. El emperador se ve obligado a intervenir constantemente en sus asuntos para intentar restablecer el orden. Las ciudades se van poblando y se hunden en la miseria. (...).". De Tocoueville, Alexis, El Antiguo Régimen y la Revolución, traducción de Jorge FerReiro, Fondo de Cultura Económica, México D.F., 1996, p. 308.

45 Sirvan como ilustración estas ideas de VIVIEN, quien reflexionaba: “"(....). Es verdad, sin duda, que el interés de la sociedad domina todos los otros; pero es falso que se la sirva olvidando todas las reglas de una buena administración. La justicia, la observancia de las leyes, el estudio concienzudo y desinteresado de las necesidades públicas y de los medios de satisfacerlas, tal es la verdadera misión de una sabia política. Por su medio, los pueblos se aficionan á sus gobiernos: á los administradores imparciales, equitativos y celosos, no les faltaron jamás la confianza y la simpatía; mientras que los favores individuales se encierran en el estrecho círculo de los que los obtienen, y el gobierno, por un pequeño número de criaturas comúnmente ingratas, atrae sobre sí las quejas de las ambiciones privadas que no ha satisfecho, y el descontento general. Por una feliz combinación, la virtud no es únicamente una obligación moral, sino que lo mismo para los gobiernos que para los particulares, es también un cálculo bien entendido.".". Vivien, Estudios Administrativos, Tomo I, Traducidos de la última edición francesa por don Antonio Hernández Amores y don Juan López Somalo, Imprenta de Luis García, Madrid, 1854, p. 26.

46 Mariano Baena del Alcázar hubo de considerar, unos años atrás, que la idea de buena administración proviene de un contrapunto que se daba con la de mala administración que provenía del Tratado de Maastricht de 1992 (artículo 195.1 del Tratado consolidado) y del enunciado negativo que de esta se hizo en el Informe Anual de 1997, del Defensor del Pueblo Europeo. Así, para este profesor y magistrado judicial "(...), a partir de este enunciado negativo se ha concretado qué se entiende por "buena administración", (...).". Baena del Alcázar, Mariano, "Sobre la idea europea de "buena administración"”, en Noticias de la Unión Europea, No. 247-248, Monográfico, La Jurisprudencia del Tribunal Supremo y el Derecho Comunitario europeo, Año XXI, Agosto-Septiembre de 2005, Madrid, p. 61. 
señalan las dos caras que puede presentar el quehacer administrativo (público); son, por tanto, la faz positiva y la faz negativa, respectivamente, de ese fenómeno. Así las cosas, hay buena administración cuando la Administración Pública se conduce ajustándose fielmente a las normas, los principios y los valores que determinan su proyección organizativa y funcional y procura sus fines existenciales de un modo pleno y cabal; mientras, estaríamos frente a una expresión de mala administración cuando, en su actuación, la Administración Pública se aparta, en la medida que fuere, de esas normas, principios y valores, y sus fines no son rectamente cumplidos.

Un punto interesante a hacer valer acá, es que la diversa normativa jurídica que ha consagrado la expresión buena administración, de ordinario, no ha contenido una definición de la misma con cierta vocación de acabado o precisión (tampoco lo ha hecho la jurisprudencia), sino que la ha proyectado más bien desde posibles implicaciones en concreto o compendiando o especificando posibles elementos en los que se concreta particularmente o parcialmente como fenómeno más general.

Un típico ejemplo de ello lo tenemos en el artículo 41 de la Carta de los Derechos Fundamentales de la Unión Europea (o Carta de Niza) de 2000, donde, a partir de lo dispuesto en su letra sobre el "derecho a una buena administración» y de las particularizaciones que allí se hacen de lo que este derecho incluye, la noción de buena administración estaría asociada en ese texto al tratamiento de los asuntos de los ciudadanos «de forma imparcial, equitativa y dentro de un plazo razonable». ${ }^{47}$

\footnotetext{
47 A la vista de un panorama de ese tipo, hubo de poder decir Beatriz Tomás Mallén, desde el contexto comunitario europeo del primer lustro de este siglo XXI: "Salvo en algunas materias aisladas (como la publicidad o la motivación de los actos de las instituciones comunitarias), los Tratados comunitarios no ofrecen criterios positivos sobre las pautas que han de impregnar la buena administración a escala de la Unión Europea. Antes bien, se enfoca la actuación administrativa de las instituciones y órganos comunitarios en clave negativa 0, a lo sumo, por vía deductiva, esto es: ya sea bajo la perspectiva de la supervisión por parte del Defensor del Pueblo europeo de los casos de «mala administración», ya sea bajo el ángulo de las manifestaciones de «buena administración» que se derivan del general principio del
} 
O en el tercer párrafo del preámbulo de la Carta Iberoamericana de los Derechos y Deberes del Ciudadano en Relación con la Administración Pública, aprobada en 2013, que, con clara influencia de la Carta de Niza y de cierto segmento del pensamiento europeo al efecto, destaca sobre la idea de buena administración, que es

"(...) aquella que se dirige a la mejora integral de las condiciones de vida de las personas. La buena Administración Pública es, pues, una obligación inberente a los Poderes Públicos en cuya virtud el quehacer público debe promover los derechos fundamentales de las personas fomentando la dignidad humana de forma que las actuaciones administrativas armonicen criterios de objetividad, imparcialidad, justicia y equidad, y sean prestadas en plazo razonable.".

Ahora bien, más allá de la realidad práctica que ha podido rodear al tema, la doctrina jurídica - como es dable colegir -, desde pioneros trabajos que se han ocupado de este tópico, ha intentado proveer, de un modo u otro, un concepto de buena administración desde el plano de lo jurídico. En ello, claro está, se han sorteado debates, dados en contextos nacionales (interesante en esto son los casos italiano ${ }^{48}$ y $^{\text {uruguayo }^{49}}$ ) y

Estado de Derecho que gobierna el funcionamiento de la Unión Europea como Comunidad de Derecho.". TomÁs MalkÉN, Beatriz, El derecho fundamental a una buena administración, Instituto Nacional de Administración Pública, Madrid, 2004, pp. 68 y 69.

48 A tenor de la mención expresa al buon andamento o principio de buon andamento en el artículo 97 de la Constitución de 1947, que se ha identificado - no sin polémica - con la buena administración o principio de buena administración. Para Balladore-PallieRI, por ejemplo, era aquella una regla general sin sentido jurídico; ver: Balladore-Palleri, G., La nuova costituzione italiana, Dott. A. Giuffrè Editore, Milano, 1948, nota 164. En este orden ideas recordaba Conso que: "Nei primi anni di vita della Costituzione alla clausula di buon andamento fu negato ogni valore giuridico. Si retenne chi e padri fondadori avessero voluto esprimere un augurio 0 un auspicio ma non un principio giuridicamente vincolante.". Conso, Guido, Manuale di Diritto Amministrattivo, G. Giappichelli Editore, Torino, 2003, p. 35.

49 En razón de la presencia de la expresión buena administración en el artículo 311 de la Constitución de 1952; y donde pueden verse criterios como los de: JIMÉNEZ dE ARÉCHAGA, Justino, La Constitución del Uruguay de 1952, Tomo IV, Editorial Organización Medina, Montevideo, 


\section{supranacionales, ${ }^{50}$ sobre si es o no una noción con sustancia o sentido jurídico; o sobre cuánto de jurídico hay en ella. ${ }^{51}$ Tam- bién, sin perder de vista circunstancias como que la misma entraña necesariamente cierto espacio de generalidad, imprecisión y apertura $5^{52}$ y que ha sido enfocada y hasta consagrada desde diversos ángulos formales (como principio, como derecho, ${ }^{53}$}

s/f, p. 957; Sayagués Laso, Enrique, El Tribunal de lo Contencioso Administrativo, Impreso en los talleres gráficos de la editorial Martín Bianchi Altuna, Montevideo, 1952, pp. 96 y sigs. (apartado de la Revista de la Facultad de Derecho y Ciencias Sociales de Montevideo, Año III, No. 1); Sayagués Laso, Enrique, Derecho Administrativo, Tomo II, Impreso en los talleres gráficos de la editorial Martin Bianchi Altuna, Montevideo, 1959, p. 595 y la nota 4 de esa misma página; Díaz Peluffo, Zola, El Recurso Contencioso Administrativo. Su reestructuración básica, Impreso en los talleres gráficos de la editorial Martin Bianchi Altuna, Distribuidor Exclusivo Librería Amalio M. Fernández, Montevideo, 1960, pp. 41 y sigs., y 327 y sigs.

50 Según Mario P. Chitı, hasta el Tratado de la Unión Europea se discutió si las frecuentes referencias al principio de buena administración en la jurisprudencia comunitaria se referían a un verdadero y propio principio general y no sólo a una variedad del principio de legalidad; incluso no faltaban quienes ponían en discusión la juridicidad del principio; ver: CHITI, Mario P., Derecho Administrativo Europeo, Traducción de Luis OrtegA, Civitas Ediciones, S.L., Madrid, 2002, p. 250. En este sentido pueden ser ilustrativas las siguientes referencias de NeHL, Hanns Peter, "Good administration as procedural right and/or general principle?", en Hofmann, Herwig C.H. y Türk, Alexander H. (Edited by), Legal Challenges in EU Administrative Law. Towards an Integrated Administration, Edward Elgar, Cheltenham, UK - Northampton, MA, USA, 2009, p. 328

51 Se ha dicho por una autora que la buena administración es un concepto de una naturaleza más moral que jurídica y que cubre un mayor número de incorrecciones que las susceptibles de ser controladas por el juez. Ver: Steenbjerg Kolze, Anna, Le Médiateur Européen, CEDRE, Rennes, 1995, p. 78.

52 Según planteaba Azoulal: "( ...) De hecho, el término de buena administración es constantemente ambiguo en Derecho Comunitario, indicando no solamente una fuente general de protección y un estado ideal del Derecho sino designa igualmente una forma particular de protección procedimental vinculante. Seguramente esta ambigüedad no está desprovista de virtud. Aparecida discretamente en la jurisprudencia, a la sombra de garantías más conocidas y mejor circunscritas, como los derechos de defensa y la obligación de motivación, las obligaciones de buena administración se han beneficiado de la autoridad de estos últimos para extenderse y elevarse en el seno del Ordenamiento jurídico comunitario, hasta el punto que parece difícil hoy día asignarles límites.". Azoulal, L., "Le principe de bonne administration”, en AuBY, JeanBernard y DUtheIL DE LA ROCHèRE, Jacqueline (sous la direction de), Droit Administratif Européen, Bruylant, Bruxelles, 2007, p. 495.

53 Es el caso del el artículo 41 de la Carta de los Derechos Fundamentales de la Unión Europea (o Carta de Niza) de 2000. En el marco latinoamericano, el brasileño Juarez FreITAS 


\section{como deber $^{54}$ o desde esa triple perspectiva ${ }^{55}$ ), no sin darse recelos técnico-jurídicos en razón del resultado propuesto. ${ }^{56}$}

ha conceptualizado el direito fundamental à boa administração pública como el "(...) direito fundamental à administração pública eficiente e eficaz, proporcional cumpridora de seus deveres, com transparência, sustentabilidade, motivação proporcional, imparcialidade e respeito à moralidade, à participação social e à plena responsabilidade por suas condutas omissivas e comissivas. (...).". FreitAs, Juarez, Direito fundamental à administração pública, $3^{\text {a }}$ edição, refundida e aumentada, Malheiros Editores LTDA, São Paulo, 2014, p. 21.

54 Por ejemplo, de tantos otros que pueden convocarse, desde Portugal ReBelo de Sousa y Salgado de Matos le han referido como "(...) dever de proseguir os intereses públicos legalmente definidos de melhor maneira possívvel.". Rebelo de Sousa, Marcelo y Salgado de Matos, André, Direito Administrativo Geral, Tomo I, Introdução e princípios fundamentais, 3. ${ }^{a}$ edição, reimpreção, Publicações Dom Quixote (Uma editora do Grupo LeYA), Alfragide, 2010, p. 209.

55 En esto puede convocarse el sexto párrafo del preámbulo de la Carta Iberoamericana de los Derechos y Deberes del Ciudadano en Relación con la Administración Pública, aprobada en 2013, cuando recoge: "La buena Administración Pública adquiere una triple funcionalidad. En primer término, es un principio general de aplicación a la Administración Pública y al Derecho Administrativo. En segundo lugar, es una obligación de toda Administración Pública que se deriva de la definición del Estado Social y Democrático de Derecho, especialmente de la denominada tarea promocional de los poderes públicos en la que consiste esencialmente la denominada cláusula del Estado social: crear las condiciones para que la libertad y la igualdad de la persona y de los grupos en que se integra sean reales y efectivas, removiendo los obstáculos que impidan su cumplimiento y facilitando la participación social. En tercer lugar, desde la perspectiva de la persona, se trata de un genuino y auténtico derecho fundamental a una buena Administración Pública, del que se derivan, como reconoce la presente Carta, una serie de derechos concretos, derechos componentes que definen el estatuto del ciudadano en su relación con las Administraciones Públicas y que están dirigidos a subrayar la dignidad humana.". Desde la perspectiva de los autores, el uruguayo DuRán Martínez resultaba enfatice al sentenciar: "(...), la buena administración es un principio, es un deber y es un derecho.". Durán Martínez, Augusto, "La buena administración", en Durán Martínez, Augusto, Neoconstitucionalismo y Derecho Administrativo, La Ley Uruguay, Montevideo, 2012, p. 393.

56 Ver, por ejemplo: Pegoraro, Lucio, “ ¿Existe un derecho a una buena administración? (Algunas consideraciones sobre el ab(uso) de la palabra "derechos")", en Ávila Rodríguez, Carmen María y GutiéRREZ Rodríguez, Francisco (coordinadores), El derecho a una buena administración y ética pública, Fundación General de la Universidad de Málaga, Málaga.es diputación, Defensor del ciudadano/a, Tirant lo Blanch, Valencia, 2011, pp. 17 y sigs. A tenor de lo que resultara en la Carta de los Derechos Fundamentales de la Unión Europea (o Carta de Niza) de 2000 sobre el "derecho a una buena administración», comentaba que: "(...) El resultado final es un supuesto derecho que constituye toda una mezcolanza de derechos, de principios generales del Derecho, de principios rectores y de meros criterios de actuación. Una suerte de supraconcepto 0, mejor aún, de término (por carecer de contenido propio) que englobaría derechos en cuanto principios generales.". Fuentetaja Pastor, Jesús Ángel, “Del «derecho 
Colocando las perspectivas formales a un lado, no pocas definiciones de lo que es buena administración figuran en los postulados de la doctrina jurídica en diversos lugares. Por lo que de su noción se ha dejado constancia por los autores, ya en fórmulas más sintéticas, ya en conceptos con mayor vocación descriptiva; o ya en fórmulas más antiguas, ya en otras ajustadas más a la realidad operativa actual que rodea al fenómeno jurídico de la buena administración; o ya en criterios más abarcadores o en otros más estrechos o limitados en su contenido. Por supuesto, esto denota, además de la clara evolución que sufre todo fenómeno de ese tipo por la fuerza de la realidad y el tiempo, la preocupación del pensamiento iusadministrativo, manifestado en diferentes momentos, por sentar un punto de partida gnoseológico para este fenómeno; más allá de las claras dificultades que resulta la empresa de pretender contornearle con meridiana precisión, por la misma carga y vocación de indeterminación que trasunta un término como el de buena administración.

Provechoso puede ser repasar algunas nociones de buena administración dadas por los autores.

El italiano Rafaelle REsta es uno de los clásicos al efecto, habiendo señalado que

"Buona amministrazione esprime un concetto finale: $\grave{e}$ l'attività amministrativa perfettamente adeguata, nel tempo e nei mezzi, al fine specifico da raggiungere." ${ }^{57}$

a la buena administración» al derecho de la Administración europea", en Cuadernos Europeos de Deusto, No. 51/2014, Buena administración en la Unión Europea, Instituto de Estudios Europeos, Bilbao, p. 25. Puede verse también lo que sostenía este autor en Fuentetaja PAstor, Jesús Ángel, “El derecho a la buena administración en la Carta de Derechos Fundamentales de la Unión Europea", en Revista de Derecho de la Unión Europea, No. 15, 2 ${ }^{\text {do }}$ semestre, 2008, Madrid, p. 151.

57 Resta, Rafaelle, ob. cit., p. 128. En otro clásico del Derecho Admnistrativo italiano sobre este tema, se puede leer: "Ouando di "buona amministrazione» si parla, in riferimento all'esercizio di una funzione, si vuole, pertanto, desinare quell'attività che, nello svolgimento di questa, riesca a curare quanto più completamente e convenientemente gli interessi che della medesima costituiscono oggetto; si esprime altresi un concetto finale, nel senso di azione 0 attività finalisticamente considerata, in quanto solo attraverso una buona amministrazione, si 
Dentro del Derecho Público uruguayo, y latinoamericano en general, un precursor de la cuestiones relacionadas con la buena administración fue Héctor GioRgi, quien desde la década de 1950 llamara la atención sobre el concepto de buena administración en ese contexto, desplegando además interesantes esfuerzos por fijar el sentido de la misma a la luz del texto constitucional de su país, datado en 1952 (texto pionero en contener, artículo 311, en su letra, expresamente, el término buena administración). ${ }^{58}$ GIORGI, influido por los planteamientos de los italianos Resta y FALZONE, ${ }^{59}$ asumía que buena administración

"(...) significa perseguir los fines objeto de la función pública, del modo más idóneo y más conveniente”. Esto es, la actividad debe cumplirse en la forma más oportuna y más adecuada para la obtención de aquellos fines.”. ${ }^{60}$

En un estudio más actual, Rhita Bousta concluía que "À notre sens, la notion de bonne administration signifie l'adaptation équilibrée des moyens dont dispose l'administration. (......". ${ }^{61}$

può ottenere il soddisfacimento del fine insito nella funzione medesima, la tutela cioè di un particulare interesse. (...).". Falzone, Guido, ob. cit., p. 64

58 De Giorgi son importantes en esta dirección: El Contencioso Administrativo de Anulación, Biblioteca de Publicaciones Oficiales de la Facultad de Derecho y Ciencias Sociales de la Universidad de La República, Impreso en los talleres gráficos de la editorial Martín Bianchi Altuna, Montevideo, 1958; "El mérito y la validez del acto administrativo. El concepto de buena administración en la Constitución uruguaya", publicado originalmente en la revista La Justicia Uruguaya, Tomo 43, 1961, Montevideo, pp. 145 y sigs., e incluido luego su obra recopilatorio de algunos trabajos, Escritos jurídicos, Fundación de Cultura Universitaria, Montevideo, 1976, pp. 77 y sigs.; y "Acatamiento del Estado a los principios y deberes jurídicos de la buena administración", en GıorGı, Héctor, Estudios de Derecho Administrativo, Ingranusi Ltda, Montevideo, 1998.

59 Ver: GIORGI, Héctor, “El mérito y la validez del acto administrativo. El concepto de buena administración en la Constitución uruguaya", en GıoRGı, Héctor, Escritos jurídicos, Fundación de Cultura Universitaria, Montevideo, 1976, pp. 91 y 92.

60 Giongı, Héctor, “El mérito...", ob. cit., p. 92. También puede verse: GıorGı, Héctor, El Contencioso Administrativo..., ob. cit., p. 47.

61 Bousta, Rhita, Essai sur la notion de bonne administration en Droit Public, L'Harmattan, Paris, 2010, p. 461. 
En una formulación más extendida y descriptiva, escribía Durán MarTínez que

"La buena administración significa elegir los instrumentos adecuados para la consecución del fin debido, obtener los resultados procurados con el menor costo posible, no efectuar trámites inútiles, hacer un buen uso del tiempo pero también actuar con transparencia, con probidad; significa asimismo que los servicios públicos funcionen correctamente, acorde a las necesidades reales del hombre de hoy, que los requerimientos de los administrados sean atendidos como corresponde y que todas las actuaciones administrativas sean seguidas cumpliendo con todas las garantías." ${ }^{62}$

Para un estudioso caracterizado en los temas de buena administración, como lo es el profesor español Jaime RoDRíGUEZ-ARANA MuÑoZ:

"Una buena Administración pública es aquella que cumple con las funciones que le son propias en democracia. Es decir, una Administración pública que sirve objetivamente a la ciudadanía, que realiza su trabajo con racionalidad, justificando sus actuaciones y que se orienta continuamente al interés general. Un interés general que en el Estado social y democrático de Derecho reside en la mejora permanente e integral de las condiciones de vida de las personas.". ${ }^{6}$

62 Durán Martínez, Augusto, "Buena administración y debido procedimiento", en RodríguezArana Muñoz, Jaime/ Sendín García, Miguel Ángel/ Pérez Hualde, Alejandro/ Vázouez Viera, Emilio/ y FarRAndo, Ismael (Coordinadores), Derecho administrativo iberoamericano. Contratos administrativos. Servicios públicos. Acto administrativo y procedimiento administrativo. Derecho administrativo ambiental. Limitaciones a la libertad, IV Congreso Internacional de Derecho Administrativo, 2010, Mendoza, Argentina, Ediciones Rap, S.A., Buenos Aires, 2011, p. 790; también en: Durán Martínez, Augusto, "La buena administración”, ob. cit., p. 175.

63 Entre los varios trabajos que este profesor español ha dedicado al tema: RodríGuez-Arana MuÑoz, Jaime, "El derecho fundamental a la buena administración pública", en RodríGuezArana Muñoz, Jaime y BéJar Rivera, Luis José (coordinadores), El Derecho Administrativo en Iberoamérica en homenaje al profesor Mariano Brito, Tomo I, Universidad Panamericana, Espress. Especialistas en Responsabilidades S.C., México, D.F., 20015, p. 568. 
En definitiva, hablar de buena administración, es, ante todo, referirse a una evaluación o valoración positiva del desenvolvimiento objetivo o material del fenómeno administrativo, atendiendo a los criterios que prevén cómo debe realizarse. De ahí que, en ello, se evoca la consideración de parámetro objetivos previamente fijados o determinados en función de ciertos fines, cuyo cumplimiento ha de señalar entonces la consideración positiva de dicho fenómeno en su concreción o realización material.

Llevando ese rápido razonamiento al plano jurídico de la Administración Pública, la buena administración pública ha de ser el estado que resulta del buen hacer administrativo, $y$ ese buen hacer deriva de una buena proyección y del ajuste y cumplimiento, por parte de la Administración Pública, de ciertos parámetros jurídicamente trascedentes, que son los que marcan sus modos de proceder y el alcance de sus finalidades; esto es, marcan la existencia y el uso de sus medios y el alcance de sus fines generales. Por lo tanto, ha de darse la buena administración cuando se han empleado bien los medios en la actuación administrativa y se ha llegado, por esa vía, al correcto cumplimiento de los fines a los que esos medios han de servir, todo ello dentro del marco jurídico existente, que ha de estar inspirado en valores y principios que garanticen y conduzcan a la plena realización del hombre social e individualmente considerado. En fin, que buena administración, no sugiere otra cosa que hacer las cosas bien en lo administrativo, dentro de un marco jurídico que propicie ese buen hacer.

En nuestra opinión, la buena administración, como noción jurídicamente relevante, ha de involucrar la idea de un accionar administrativo público que se efectúe del modo más óptimo posible y que alcance, por esa vía, también de forma óptima, el fin (general) que determina dicho accionar, todo ello dentro de un orden jurídico que sea realmente cause de determinación y garantía de esa realización.

Igualmente, hay que anotar que la buena administración pública no implica sino la buena gestión de los intereses 
generales, en lo que ha de estar implícito, de suyo, el respeto a los derechos de los ciudadanos o administrados - de lo contario esa gestión no podría entenderse como buena -. Realizar los intereses públicos, sin provocar la ruptura del equilibrio que debe guardarse en esa realización con la promoción y salvaguarda de los derechos y libertades de los ciudadanos, ha de ser un planteamiento fundamental que se coloca en la base misma de la idea de buena administración pública. Lo cual indica, entonces, que el contenido de esta última noción, y sus manifestaciones concretas, deba conciliar - y trasuntar - ambas esferas, y sus concreciones jurídicas han de estar perfiladas tanto hacia la realización de los intereses generales, como a la promoción, respeto y garantía de los derechos de los ciudadanos o administrados frente a la actuación pública.

Vista desde esa perspectiva la cuestión, hay que decir que la buena administración, como noción jurídicamente relevante, queda - quizás no puede ser de otro modo, atendiendo a que conlleva en sí un juicio de valor sobre una actuación o funcionamiento -, esencialmente, en el plano de lo genérico, de lo abierto o amplio, de lo brumoso hasta cierto punto; es más bien una silueta que señala contornos externos, y que debe ir llenándose de sustancia y contenido gradualmente y en ascenso. Como la evolución al respecto ha ido dejando de manifiesto con el paso de los años y los avances en materia jurídica a favor del ciudadano y frente al ejercicio del poder público, el trazado de la buena administración como concepto con presencia en lo jurídico, solo puede irse esclareciendo, no desde una definición que al parecer siempre será genérica y poco precisa, sino a partir de elementos concretos e individualizados que la vayan sustanciando y especificando en su significado, en la medida que evoluciona el orden jurídico. Por ende, jurídicamente hablando, la buena administración se perfila como una noción con vocación genérica o englobadora, a la que puede llegarse a partir del compendio o descripción concreta de los elementos que pueden quedar comprendidos 
en ella ${ }^{64}$ Es una noción jurídica de compendio o síntesis (concepto síntesis), que agrupa en su seno una serie plural de expresiones jurídicas (principios, derechos, deberes).

De tal suerte, la buena administración es un concepto que, para lo jurídico, expresa un sentido unitario, pero se manifiesta en situaciones y expresiones jurídicas de diversa índole, precisamente por lo diverso que resulta el contenido del funcionamiento administrativo y todo él no debe menos que estar perfilado hacia el buen hacer. De ahí que sea forzoso reconocer que la buena administración trasunta un concepto complejo y multifacético, ${ }^{65}$ y un contenido amplio, plural y en buena medida indeterminado, ${ }^{66}$ como bien se ha dicho.

Cuando se habla abiertamente sobre buena administración, desde cualquiera de sus dimensiones formales más globales en que aparece configurado (principio de buena administración, deber de buena administración, derecho a la buena administración), no puede conducirnos sino a entender lo allí reflejado como una fórmula genérica, con especiales connotaciones, que sirve de solución englobadora, compendiadora, de compactación, integración, condensación, síntesis o resumen, desde el punto

64 En este orden de cosas cabe entender también el hecho de que se haya catalogado al Defensor del Pueblo Europeo como "artesano del desarrollo del derecho a una buena administración comunitaria" (en el ámbito europeo). El entrecomillado corresponde al título de un trabajo ya citado, en el que su autora además escribe: "Dans le silence du Traité de Maastricht et l'incomplétude de la Charte de Nice, il revenait ainsi au Médiateur européen d'esquisser par impressionnisme les contours flous du droit à une bonne administration communautaire. A l'analyse de ses décisions, I'on ne peut qu'être frappé par son interprétation évolutive du concept de bonne administration. Après des débuts hésitants et clandestins sur la scène juridique européenne, il a su transformer ses prises de position ponctuelles en une véritable œuvre de conceptualisation. De cette "jurisprudence" créative visant à la protection du droit des citoyens à une bonne administration communautaire, certains principes sectoriels se sont dégagés qu'il y a lieu de préciser d'emblée (I), avant d'évoquer l'effectivité de ce droit dont le Médiateur européen se veut le promoteur (II).". Ver : Yeng-Seng, Wanda, ob. cit, p. 530.

65 Mendes, Joana, "La bonne administration en Droit Communautaire et le Code Européen de Bonne Conduite Administrative", Revue française d'administration publique, $n^{0} 131,2009 / 3$, Paris, p. 560.

66 Tornos Mas, Joaquín, “El principio de buena administración...", ob. cit., p. 629. 
de vista formal; en tanto que en ellas no se hace sino sintetizar, integrar o resumir, expresa y genéricamente, pero sin agotar, la referencia a un grupo diverso de principios, deberes y derechos ${ }^{67}$ que se han ido decantado y delineando en el desarrollo de los ordenamientos jurídicos de Europa occidental (especialmente) en los últimos dos siglos, ya sea en el plano de sus ordenamientos nacionales, ya en el del Derecho comunitario europeo.

De igual modo, piense que la idea misma de buena administración no se agota en todos esos principios, deberes y derechos que se han ido positivando o reconociendo expresamente de algún modo. Antes bien, ellos conforman cierto estándar mínimo, cierto núcleo duro o más visible, de manifestación y proyección de esa idea de buena administración aplicada a lo jurídico; mas no resumen en sí todas las implicaciones que de ahí pudieran desgajarse.

En consecuencias, la buena administración queda también como una noción con un contenido abierto a la dinámica y la evolución continua, ${ }^{68}$ en tanto en la medida en que la sociedad políticamente organizada evoluciona jurídicamente, nuevos elementos se irán incorporando como exigencias a las que debe ajustarse el ejercicio del poder - y en este caso el

67 Como se ha acotado por Siegfried Magiera, a tenor del artículo 41 de la Carta de Niza, donde se consagra por vez primera el derecho a la buena administración, que, "(...) el "derecho a una buena administración" no se agota en el resumen de los derechos que se enumeran en esta disposición. (....."; MAgIERA, Siegfried, ob.cit., p. 520. En la autorizada voz de P. Nikiforos Diamandouros: "(...) sería un error pensar que el artículo 41 proporciona una lista exhaustiva de principios de buena administración o sobre el trato al que tienen derecho los particulares por parte de las instituciones de la UE."; Nikiforos Diamandouros, P., "Buena administración, Estado de Derecho y ética...", ob. cit.

68 A la luz del artículo 97 de la Constitución italiana (y la presencia allí del buon andamento como principio), Aldo Sandulu concluía que era ese "(...) un principi complessi, dai contorni cangianti e dalle molteplici sfaccettature (...)", así como que resultaba un "(...) concetti giuridici di carattere indeterminato, legal standards dinamici e flessibili, che, da un lato, contribuiscono a dotare di dinamicità il sistema giuridico e, dall'altro, consentono di svolgere la funzione di filtro tra la disciplina normativa e la realtà sociale (...).". SANDuLLI, Aldo, "Il procedimento", en Cassese, Sabino (a cura di), Trattato di Diritto Amministrativo. Diritto Amministrativo Generale, Tomo II, Dott. A. Giuffrè Editore, Milano, 2003, p. 1065. 
funcionamiento administrativo - para responder adecuadamente a las necesidades de vida de los ciudadanos, según los valores y principios que rijan esa comunidad en cada momento históricoconcreto que se presente. ${ }^{69}$

\section{La buena administración como principio jurídico o el principio de buena administración}

No es este el marco propicio para adentrarnos en el debate en torno a la configuración jurídica de la buena administración; esto es, si es un derecho (fundamental, según lo entronizó la Carta de Niza en su artículo 41), un principio jurídico o un deber, o las tres cosas a la vez (tal como se acoge en el preámbulo de la Carta Iberoamericana de los Derechos y Deberes del Ciudadano en Relación con la Administración Pública de 2013).

Este debate trae causa del carácter trifronte con que se ha presentado la buena administración en su proceso de configuración jurídica, y a partir de las posiciones sostenidas por la doctrina, la jurisprudencia o acogidas en los instrumentos normativos de carácter nacional o internacional. Y es un debate que no se muestra pacífico, ni homogéneo, en sus conclusiones.

Pero, por lo pronto, quedémonos en el plano principial y ajustémonos a la perspectiva de la buena administración como principio jurídico.

Evocando el tracto histórico que ha seguido la referencia a la buena administración dentro del Derecho Administrativo, queda claramente al descubierto que la dimensión que ha primado dentro de la configuración jurídica del mismo, en ese tracto histórico, ha sido la de tenerle como un principio que ha ido adquiriendo sustancia jurídica cada vez con más intensidad.

\footnotetext{
69 En apreciación de Tornos MAs: “Como principio rector de la actuación de las administraciones públicas, la buena administración tiene un alcance mucho mayor en la medida en que su carácter plural y su fuerza expansiva pueden dar mucho juego para imponer una nueva cultura en la actuación de las administraciones públicas y en su relación con los ciudadanos.". ToRnos MAs, Joaquín, El derecho a una buena administración, ob. cit., p. 16.
} 
En la actualidad, realmente, la percepción más recurrente entre los autores y la jurisprudencia, y por ello la interpretación que ha aparecido como dominante y más extendida, es la de catalogar a la buena administración dentro de la idea de principio de carácter jurídico, ${ }^{70}$ o principio general del Derecho Administrativo, lo que se traduce en el principio de buena administración. ${ }^{71}$

Recordemos que en la construcción que proponía Ronald Dworkin, este autor, distinguiendo entre directriz politica y principio, llamaba

“(...) «principio» a un estándar que ha de ser observado, no porque favorezca o asegure una situación económica, política o social que se considera deseable, sino porque es una exigencia de la justicia, la equidad o alguna otra dimensión de la moralidad. (.....”. ${ }^{72}$

\section{Mientras, para Robert AleXY:}

"El punto decisivo para la distinción entre reglas y principios es que los principios son normas que ordenan que algo sea realizado en la mayor medida posible, dentro

\footnotetext{
70 En una parte de la doctrina que ha tratado el tema de la buena administración, se ha reconocido que "(...) la verdadera fuerza e interés de la buena administración es configurarla como un principio rector de la actuación de las administraciones públicas.". Tornos Mas, Joaquín, El derecho a una buena administración, ob. cit., pp. 43. Para este profesor español (pp. 630 y 633) el principio de buena administración actúa como principio rector que impone un mandato de optimización; y, a su entender "(...), la buena administración debe concebirse no tanto como un nuevo derecho de los ciudadanos, sino como un nuevo principio rector de las administraciones públicas modernas. Un Principio de largo alcance que actúa como mandato de optimización con el fin de marcar las pautas a seguir. En algunos casos el principio se traducirá en el reconocimiento de derechos frente a la actuación administrativa. (...).".

71 Por ejemplo, entre los autores, y poco después de la aprobación de la Carta de Niza en diciembre de 2000, el profesor español Mariano BAENA DEL ALCÁZAR, a propósito del artículo 41 de ese cuerpo dispositivo, en el que se regulaba lo atinente al derecho a la buena administración, concluía, con independencia de la letra misma de la mencionada Carta: "El artículo 41 de la Carta (II.41 del Proyecto de Constitución) establece un principio general (número 1), intenta precisar un contenido fundamental (número 2), y contiene dos principios complementarios sobre las materias de la responsabilidad y el uso de la lengua (números 3 y 4).". BAENA DEL Alć́zAR, Mariano, ob. cit., p. 62. (El resaltado en negritas es del original transcrito).

72 DWorkin, Ronald, ob. cit., p. 72.
} 
de las posibilidades jurídicas y reales existentes. Por lo tanto, los principios son mandatos de optimización, que están caracterizados por el hecho de que pueden ser cumplidos en diferente grado y que la medida debida de su cumplimiento no sólo depende de las posibilidades reales, sino también de las jurídicas. El ámbito de las posibilidades jurídicas es determinado por los principios y reglas opuestos.". ${ }^{73}$

Según ampliaba el mismo Alexy:

"Los principios ordenan que algo debe ser realizado en la mayor medida posible, teniendo en cuenta las posibilidades jurídicas y fácticas. Por lo tanto, no contienen mandatos definitivos sino sólo prima facie. Del hecho de que un principio valga para un caso no se infiere que lo que el principio exige para este caso valga como resultado definitivo. Los principios presentan razones que pueden ser desplazadas por otras razones opuestas. El principio no determina como ha de resolverse la relación entre una razón y su opuesta. Por ello, los principios carecen de contenido de determinación con respecto a los principios contrapuestos y las posibilidades fácticas.". ${ }^{74}$

En nuestra opinión, es desde la configuración técnico-jurídica de la buena administración como principio, y por tanto en su consideración como tal, desde donde se permite entender, desplegar y respaldar, con más consecuencia y coherencia las implicaciones de la misma ${ }^{75}$ orientándose mejor hacia los objetivos o fines que han de buscarse con ello.

\footnotetext{
73 AleXY, Robert, Teoría de los derechos fundamentales, Versión castellana de Ernesto Garzón Valdés, Centro de Estudios Constitucionales, Madrid, 1993, p. 86.

74 AleXY, Robert, ob. cit., p. 99.

75 ToRnos Mas ha sostenido que: “El principio rector comporta la imposición a los poderes públicos de una conducta tendente a hacer realidad el contenido del principio. Por lo tanto, no otorga a los ciudadanos posiciones subjetivas concretas que les permitan exigir lo que el principio pretende. Como mandato se dirige al legislador y al resto de poderes públicos. El legislador puede convertir el principio en derechos subjetivos. Este mandato se califica como mandato de optimización, es decir, los poderes públicos atendiendo a las circunstancias
} 
En tanto principio jurídico, y en su rol rector e informador, el de buena administración ha de fundamentar y permear a toda la existencia de la Administración Pública, lo mismo en su ángulo estructural o de organización, como en el funcional o relacional con otros sujetos. Lo cual tributa a explicar que el principio de buena administración se encuentra en los fundamentos y en los límites del aparato y del funcionamiento administrativos; y no solo ha de operar como elemento a favor de proveer una mejor gestión pública (lo que ubica la mirada desde el lado singularizado de la Administración), sino que también lleva a enfocar a la buena administración en su significación para proveer y proteger al interés general, y como aspecto de promoción, garantía y protección de los derechos de los ciudadanos (administrados) en relación con el funcionamiento administrativo. Desde el encuadramiento técnico-jurídico como principio, la buena administración permite articularse coherentemente en los planos colectivos (del interés general) e individual (de los derechos e intereses de los ciudadanos o administrados),

concretas de las diversas relaciones jurídicas afectadas por el principio deben tratar de darle el mayor desarrollo posible."; Tonnos Mas, Joaquín, El derecho a una buena administración, ob. cit., pp. 39. Por su lado, analizaba CarRillo Donaire: "Desde la perspectiva de la normatividad y de la eficacia de las situaciones de derecho o de interés en las relaciones jurídicas, los principios del Derecho actúan como un prius jurídico ontológico y axiológico que señalan con carácter permanente los objetivos o metas a alcanzar en las relaciones jurídicas, por lo que están necesitados, para su efectividad de un proceso de concreción. En ocasiones, dicho proceso lo inicia o lo endereza el legislador (o el constituyente) positivando un principio. Por esta vía, los principios adquieren una corporeidad y recognoscibilidad que les hace abandonar su función supletoria, potenciando su función informadora, sirviendo de contraste de legalidad de las fuentes subordinadas y propiciando que ésta regulen derechos subjetivos o deberes inspirados en ellos. En otras ocasiones, y con independencia de su positivización legal, los principios son transformados en Derecho aplicable («positivados» también, en un sentido amplio del término) por los Tribunales, como dirimentes de la legalidad o de la licitud de una acción que ha producido efectos jurídicos. En todo caso, va de suyo que si un principio (como pudiera ser el de buena administración) queda positivado como tal mediante su inclusión en un texto legal (un Estatuto de Autonomía, por ejemplo) queda convertido en un mandato a los poderes públicos, en un deber en sentido técnico-jurídico (y no una simple facultad), de modo que las normas subsiguientes podrían desarrollarlo mediante - entre otras posibilidades - el diseño de derechos subjetivos perfectos."; Carrillo DonalRe, Juan Antonio, ob. cit., pp. 1157 y 1158. 
de una manera tal que no se corre el riesgo de potenciar con ese encuadramiento uno de esos planos por sobre otro, que lleve a romper el necesario equilibrio que debe existir en el marco jurídico ordenador del funcionamiento administrativo. Con un planteamiento técnico-jurídico desde la categoría principio, la buena administración ha de cubrir tanto las implicaciones de orden objetivo, como las subjetivas, que quedan evidenciadas en las actuales regulaciones positivas de la misma, aún cuando hoy aparezca con mayor visibilidad moldeada - al menos en el contexto europeo - como derecho en cabeza de los ciudadanos o administrados. ${ }^{76}$

Junto a todo lo anterior, hay que ver también, desde nuestra interpretación, que enfocándole jurídicamente como principio de buena administración, se hace frente tanto a la heterogeneidad del objeto que puede abarcar la idea misma de buena administración, como a la pluralidad de situaciones en que ha de manifestarse $;^{77}$ quedando también el necesario margen de apertura para convocarle y aplicarle, como medio técnicojurídico, en función de soluciones que han de darse, según lo

76 En la percepción de Sanz Larruga: "( ...) resulta indudable que la "buena administración" constituye un verdadero "principio rector" de las Administraciones Publicas que ha calado en la legislación y la jurisprudencia como expresión aglutinante de su buen funcionamiento, no solo desde una perspectiva interna, sino también -y en particular- desde el punto de vista de sus relaciones con los ciudadanos. Pero, en todo caso, un principio rector que, (...), se ha positivizado en una serie de principios específicos, mandatos y directrices para las Administraciones Publica, e incluso verdaderos derechos de los ciudadanos con concretas garantías para su salvaguardia.". SAnz LARRuga, Francisco Javier, “El ordenamiento europeo, el Derecho Administrativo español y el derecho a una buena administración", en Anuario de la Facultad de Derecho de la Universidad Da Coruña, No. 13, 2009, Facultad de Derecho de la Universidad Da Coruña, La Coruña, p. 741 (este artículo fue originalmente incluido en el libro homenaje al profesor chileno Eduardo Soto KLoss).

77 En el sentir de Tornos Mas: "Tanto las referencias normativas como las jurisprudenciales configuran el principio de buena administración como un principio de contenido plural, lo que, por un lado, amplía su radio de acción, pero, por otro, puede hacerle perder fuerza imperativa. Al final, “la buena administración” podría convertirse en un mero recordatorio del deber general de la Administración para que sirva con objetividad y eficacia a los intereses generales.". ToRnos Mas, Joaquín, El derecho a una buena administración, ob. cit., pp. 16. También debe verse: ToRnos MAS, Joaquín, “El principio de buena administración..., ob. cit., p. 633. 
planteen las nuevas situaciones que de seguro ha de generar, en perspectiva de futuro, la vida iusadministrativa, y que hoy no han de estar plenamente visualizadas en su alcance.

De tal suerte, la configuración jurídica como principio de buena administración, ha de llevarnos a entenderle como un supraprincipio o superprincipio jurídico (principio de amplio espectro, que abarca a su vez a otros principios de contenido más concreto o específico y a otras implicaciones jurídicas); ${ }^{78}$ o como "principio sombrilla o paraguas» ("umbrella principle», en palabras de Klara KANSKA), que comprende y se proyecta en principios de alcances más concretos, en derechos (de los ciudadanos o administrados) y en deberes (de la Administración) o mandatos (para la Administración), cuya observancia o cumplimiento y realización, en última instancia, llevan a observar y realizar aquel principio mayor; ${ }^{79}$ o como "principio originario" con ramificaciones de principios que derivan de él, según se proyectaba Aldo SANDulli. ${ }^{80}$

Y es, bajo esa perspectiva abarcadora de principios, que podamos comprender a los diversos autores cuando hablan de principios de buena administración.

\section{Juridicidad y principio de buena administración}

El universo de los poderes públicos y su funcionamiento tienen en el Derecho, como es pacífico considerar hoy, no solo sus

\footnotetext{
78 La portugesa SusanaTAVARES DA SILVA, descataba que "Uma nota fundamental a propósito deste princípio radica no que a doutrina designa como "auto-suficiência jurídica" do mesmo (Simonati, 2009). Com esta expressão arreda-se a ideia muito divulgada noutros sectores da doutrina de que este princípio e um "superprincípio" que alberga ou congrega em si outros princípios e regras de direto europeu, mas que não tem conteúdo autônomo. (...).". Tavares da Silva, Susana, ob. cit., p. 28.

79 KansKa, Klara, "Towards Administrative Human Rights in the EU. Impact of the Charter of Fundamental Rights", en European Law Journal, Vol. 10. No. 3, Blackwell Publishing Ltd., 2004. p. 305.

80 Decía Aldo Sandulu que "(...) il principio del buon andamento può essere considerato un principio, per cosi` dire, originario, da cui si dipartono una pluralità di ramificazioni, che costituiscono principi derivati dal medesimo.". Ver: Sandulu, Aldo, ob. cit., p. 1086.
} 
límites, sino también sus determinantes o fundamentos, pues ese universo es solo posible concebirlo dentro del perímetro y el sentido que le aporta el Derecho, de lo contrario serían meros mecanismos de fuerza organizada desnaturalizados. Eso no es otra cosa, que el sentido más actual de la idea de Estado de Derecho y sus diversas expresiones evolutivas.

Para nosotros, no debe olvidarse que cuando se trata de la Administración Pública, la realización material de la misma pasa por su ordenación jurídica, en tanto dicha Administración Pública es un fenómeno que solo puede existir válidamente (como toda manifestación organizada y funcional del poder público) dentro de los marcos que le provee el Derecho, donde la garantía de consecución del interés general o común y la promoción y el respeto a los derechos de los ciudadanos, que no solo limitan, sino que además deben determinar el funcionamiento administrativo público, son dos factores que devienen inexcusables en ese proveimiento para ser verdaderamente tal.

El profesor español ToRno Mas, al indagar sobre las razones del éxito del principio de buena administración, se respondía:

"A nuestro entender, dentro de su amplio y en buena medida indeterminado contenido, se encuentra recogido todo aquello que se pretende imponer a una administración que juzgamos carece de la necesaria fuerza interna. Una administración a la que el ciudadano exige algo más que el servir de forma objetiva a los intereses generales. Por eso creemos que la buena administración trata de dotar de alma a una administración que, vinculada tan sólo al cumplimiento de la norma previa, se nos aparece fría y distante.". ${ }^{81}$

A raíz de ello, la buena administración, al configurarse como principio jurídico, resulta elemento que se coloca dentro del principio de juridicidad que marca la sujeción de la Administración Pública, y de todo el fenómeno de lo administrativo público, al Derecho.

81 Tornos Mas, Joaquín, “El principio de buena administración...", ob. cit., p. 629. 
Visto así, el principio de buena administración, por un lado, deviene entonces en una consecuencia de las exigencias más contemporáneas ${ }^{82}$ del Estado de Derecho, ${ }^{83}$

Como ha dicho Nikiforos Diamandouros :

"Los principios de buena administración cobran especial importancia a la hora de garantizar que la administración pública respete el Estado de Derecho.”. ${ }^{84}$

Por otro lado, el principio de buena administración señala una profundización y mayor alcance, en lo material o sustancial, del principio de juridicidad, en su operatividad para lo administrativo público. Permeándose, a su vez, y en todas sus expresiones, del sentido y contenido del segundo, lo que se refleja desde la propia configuración de la buena administración como principio jurídico.

82 Para Susana Galera Rodrigo, a propósito del ordenamiento comunitario europeo: "El principio de buena administración es una manifestación de la "Comunidad de Derecho", expresión acogida por el Tribunal de Justicia por absorción del principio de Estado de Derecho común a los Estados miembros, y que acaba por incorporarse - tras la aprobación del Tratado de Maastricht - en el artículo 6 del TUE, apartado primero, que dice: "La Unión se basa en los principios de libertad, democracia, respeto de los derechos humanos y de las libertades fundamentales y el Estado de Derecho, principios que son comunes a los Estados miembros».". Galera Rodrigo, Susana, "El derecho a una buena administración", en Álvarez Conde, Enrique y Garrido Mayol, Vicente (Directores)/ García Couso, Susana (Coordinadora) et al, Comentarios a la Constitución Europea, Libro II, Los derechos y libertades, Tirant lo Blanch, Valencia, 2004, p. 1446.

83 En comentario del francés Michel Fromont: "Selon nous, les principes de bonne administration les plus importants pour les particuliers peuvent être rattachés au principe de l'État de droit. Les autres principes son notamment ceux affirmés pas les lois sur la procédure administrative, tels que les principes de hiérarchie, d'efficacité et de rapidité. Les principes découlant de la notion d'État de droit sont principalement certains principes relatifs à l'élaboration d'une décision (audition préalable, impartialité et motivation) ainsi que de quelques grands principes de fond, ceux de proportionnalité, de sécurité juridique et de responsabilité. (...).". Fromont, Michel, Droit administratif des États européens, Presses Universitaires de France, Paris, 2006, pp. 100 y 101. En esta línea, puede verse también de Fromont, "Le renforcement des garanties de bonne administration et de bonne justice en Europe", en AA.VV., En hommage a Francis Delpérée. Itinéraire d'un constitutionnaliste, Bruylant, Bruxelles, 2007, pp. 547 y sigs..

84 Niriforos Diamandouros, P., “Buena administración, Estado de Derecho y ética...", ob. cit. 
En ese orden de ideas, debe tenerse a la vista que la buena administración surge y va ganando espacios como medio para impulsar una trasformación radical, hacia mayores estándares de calidad, en la organización y el funcionamiento de la Administración Pública, desde el planteo de un marco jurídico que refleje, asuma y promueva esa transformación. ${ }^{85}$ La idea es que la buena administración conduzca a superar caducas percepciones sobre el régimen jurídico de la Administración Pública (Derecho Administrativo), que no permiten la realización plena de dicho régimen en función del cumplimiento cabal de sus fines existenciales; que sirva para proyectar una necesaria cultura del buen hacer administrativo, encauzada en una ordenación jurídica que se coloque rectamente en la garantía de ese buen hacer, y donde el ciudadano y la comunidad (en fin, la promoción y garantía de la realización de la condición humana) sean el verdadero eje de vida (de preocupación y ocupación) del entramado administrativo público, a partir de un universo jurídico que tenga esa exigencia como premisa.

Según discurría ToRnos Mas:

“(...) Hoy a la administración no sólo le exigimos que se sujete a la norma habilitante y que lleve a cabo de forma neutra y objetiva el mandato del Gobierno. No basta tampoco con el respeto de las reglas procedimentales que han positivizado muchos de los elementos de la buena administración. Hoy basamos la legitimación

\footnotetext{
85 El profesor y magistrado judicial español Mariano BAENA DEL AlcÁzAR, había comentado sobre los "criterios inspiradores de la idea europea de buena administración", que esos criterios, a la luz de los textos europeos que estudiaba, parecían ser "(....) el juridicismo y las nuevas tendencias en materia de administración relativas a la calidad. El juridicismo resulta patente. Así es de tener en cuenta que la "buena administración" pretende entenderse como un derecho subjetivo, y la idea se recoge en textos jurídicos declarativos de derechos y en un llamado Código de Buena Conducta. Sobre todo, y este es el dato decisivo, el derecho se refiere a aspectos prácticamente siempre procedimentales, salvo la reparación de daños. La regulación no pretende que se administre bien, sino que las instituciones y los agentes europeos guarden una buena conducta en el sentido de que se atengan a unas normas de procedimiento que supongan el respeto a los interesados."; BAENA DEL AlcázAR, Mariano, ob. cit., pp. 65 y 66.
} 
de la administración en algo más evanescente como es el ben hacer, la búsqueda de la mejor solución posible, la eficacia y eficiencia en la prestación de los servicios, el intento de conseguir la adhesión de los ciudadanos a sus propuestas, la preocupación por la calidad de los servicios que presta, el trato personal con el administrado, la comunicación, la trasparencia. En definitiva, exigimos algo más que la escrupulosa sujeción al marco legal. (...).”. ${ }^{86}$

El surgimiento y ascendencia del principio de buena administración se ubica dentro de lo que CASSESE llamó el "proceso di legalizzazione della pubblica amministrazione". ${ }^{87}$ No caben dudas que la aparición y desenvolvimiento del principio de buena administración ha sido un recurso válido para remontar, hacia mayores implicaciones sustanciales o materiales, los límites estrechos de un principio de legalidad amarrado solo a exigencias formales (la no vulneración del marco jurídico-administrativo ${ }^{88}$ ), y de un Derecho Administrativo en cuyo trazado y funcionalidad no se habían incorporado consecuentemente todos los ejes que hacen de él un producto en función de la

86 Tornos Mas, Joaquín, “El principio de buena administración...", ob. cit., p. 630.

87 CASSESE, Sabino, ob. cit., p. 2. Según entendía este maestro italiano (p. 7): "(...) la buona amministrazione ha un contenuto variabile. Si può dire che vi siano alcuni "core principles", quali il diritto di accesso, quello di essere sentiti, quello a ottenere una decisione motivata, quello di difesa attraverso un giudice. Questa parte della buona amministrazione si sovrappone in larga misura con la "rule of law" e con il principio di legalità inteso in senso ampio, nel campo amministrativo ("due process of law"). Fa parte dei diritti procedurali, che hanno tutti una rilevanza esterna.".

88 Como considerara Mário Aroso de Almeida: “Diríase que, si la Administración observa todas las reglas y principios jurídicos que se le imponen, habrán todas las condiciones para que la administración que produce sea "buena" - y, por tanto, la administración es "buena" si cumple las reglas y principios de garantías de los ciudadanos. En nuestra visión, la mera observancia de reglas y principios jurídicos no garantiza, por sí, la buena administración, en la medida en que existen problemas de mala administración que se colocan en otros planos y, por eso, sólo se resuelven mediante la intervención de consideraciones que ultrapasan, claramente, las fronteras de lo jurídico.". Aroso de Almeida, Mário, "Legalidade administrativa e boa administração: dificuldades e desafios", en Aroso de Almeida, Mário, Teoria Geral do Direito Administrativo. 0 novo regime do código do procedimento administrativo, $3^{\text {a }}$ edição, Edições Almedina, S.A., Coimbra, 2015, p. 66 
convivencia social y del ser humano como elemento determinante de esa convivencia. ${ }^{89}$

Pero, con independencia de lo anterior, se ha advertido que

“(...) el principio de buena administración es una derivación del principio de legalidad que no asume caracteres netamente diferenciados. El único rasgo peculiar consiste en el énfasis puesto en el respeto a los criterios de eficiencia y eficacia, y por lo tanto a todo parámetro de buena administración incluidas reglas técnicas e internas. A la "buena administración» se ha hecho referencia para asegurar la oportunidad de la acción administrativa y la capacidad funcional de la Administración. (.....". ${ }^{90}$

Asimismo, desde España, enseñaba Joaquín Tornos Mas que la noción de buena administración

"(...) en el fondo encierra la idea de superar, sin abandonar, el principio de legalidad como punto de partida y fin de la legitimación de las Administraciones públicas. Las Administraciones deben respetar la norma, pero a su vez deben lograr las mejores prestaciones materiales

89 En palabras de Rodríguez-Arana Muñoz: "El Derecho Administrativo moderno parte de la consideración central de la persona y de su concepción abierta y complementaria del interés general. Los ciudadanos ya no son sujetos inertes que reciben, única y exclusivamente, benes y servicios públicos del poder. Ahora, por mor de su inserción en el Estado social y democrático de Derecho, se convierten en actores principales de la definición y evaluación de diferentes políticas públicas. El interés general ya no es un concepto que define unilateralmente la Administración sino que ahora, en un Estado que se define como social y democrático de Derecho, debe determinarse, (...) a través de una acción articulada entre los poderes públicos y los agentes sociales. (...).". Rodríguez-Arana Muñoz, Jaime, El ciudadano y el poder público..., ob. cit., pp. 113 y 114.

90 CHITI, Mario P., ob. cit., p. 250. Al razonar en torno al artículo 97 constitucional, el italiano Aldo SANDULLI, reparaba en el hecho de que la referencia allí a los principios de imparcialidad y buon andamento señalaba a este ultimo como exigencia de buena administración, significando a este último como "(...) necessità di eficacia e di efficienza dell'azione, in modo da consentire il perseguimento di risultati adeguati (...)"; y derivando en sus conclusiones hacia la conclusión que "(...) dalle riflessioni della scienza giuridica, imparzialità e buon andamento non andrebbero considerati come principi distinti, ma come due facce di una stessa medaglia, come una endiadi che articola un concetto unitario di legalità. (...) ". SANDulu, Aldo, ob. cit., p. 1066. 
posibles, y deben adoptar las resoluciones que mejor respondan al interés general.". ${ }^{11}$

De lo dicho hasta aquí cabe entender que principio de juridicidad y principio de buena administración son un par indisolublemente conectados. ${ }^{92}$ La realización del segundo sólo puede alcanzarse a través de la estricta observancia del primero, por la vía del cumplimiento pleno de las exigencias jurídicas que le vienen impuestas a la Administración Pública por el Derecho.

\section{Sobre el contenido y alcance del principio de buena administración: unas reflexiones generales}

El principio de buena administración revela un principio de connotaciones genéricas que resulta, en lo formal, una manera de englobar y de dotar de unidad de sentido a determinadas exigencias que debe observar la Administración Pública en su existencia y a ciertos requerimientos y situaciones que se dan en sus relaciones con los ciudadanos o administrados. De igual forma, resulta pacífico el punto de partida de que el contenido del principio de buena administración ha quedado reconocido y trazado con un carácter plural y heterogéneo, tanto en las consideraciones de la jurisprudencia y la doctrina, como en la normativa que a él se refiere. Así las cosas, el principio de buena administración se reverla o traduce, según ha tenido oportunidad de dejar en claro su evolución dentro del ámbito jurídico, en un conjunto o elenco de principios de alcance o proyección más particularizados que aquél, así como de derechos (de los ciudadanos o administrados) y deberes (de la Administración Pública) que lo concretan.

Junto a lo anterior, debe convocarse también la precisión de que el contenido del principio de buena administración ha sido un ámbito en expansión a través de todo este tiempo, ya en su funcionalidad, ya en los perímetros objetivos de alcance,

\footnotetext{
91 Tornos Mas, Joaquín, “Prólogo”, en Ponce Solé, Juli, ob. cit., p. 21.

92 Con motivo del marco constitucional italiano, Guido Conso afirmaba que "il principio de buon andamento opera come temperamento del principio de legaltà". Conso, Guido, ob. cit., p. 36.
} 
ya en sus expresiones formales de manifestación jurídica. Esta circunstancia ha estado estrechamente ligada tanto a la evolución del ámbito jurídico-administrativo, como a la del propio principio de buena administración.

En consonancia con ello, resultan aleccionadoras las enseñanzas del profesor italiano Sabino CAssese, en tanto proveen puntos de partida para entender el ensanchamiento y manifestación del contenido de la buena administración. Según CASSESE:

“(...) la buona amministrazione ha avuto una importante evoluzione funzionale. Da principio in funzione della eficacia della pubblica amministrazione (ex parte principis), è divenuto principio in funzione dei diritti dei cittadini ("ex parte civis"). Prima era considerata mezzo per assicurare che il potere pubblico fosse efficace, perché gli interessi collettivi e pubblici ad esso affidati fossero pienamente tutelati. Poi è divenuta strumento per assicurare una difesa del potere pubblico, perché le situazioni giuridiche soggettive dei privati potessero essere tutelate più efficacemente. Ad esempio, la partecipazione dei privati nella prima versione serve all'amministrazione, per conoscere meglio prima di decidere; nella seconda versione serve al privato, per far sentire la propria voce prima che l'amministrazione concluda il procedimento.". ${ }^{3}$

El italiano indicaba además que el principio de buena administración ha tenido un ámbito o extensión diversos, pues se afirmó inicialmente como principio limitado a algunos sectores, como principio especial, para luego devenir de aplicación siempre más extendida, operando como principio general. ${ }^{94}$ Finalmente, CASSESE refería:

"(...) la buona amministazione si è evoluta da principio a diritto. Nella prima veste, ha valore "programmatico", costituisce un obiettivo fissato dalla constituzione $e$ diritto al legislatore. Ha, quindi, una valenza limitata

93 Cassese, Sabino, ob. cit., p. 6.

94 CASsese, Sabino, ob. cit., p. 7. 
e interna all'apparato statale. Nella seconda veste, si proietta all'esterno della cerchia dello Stato, nella comunità. Conferisce diritti ai quali fanno riscontro obblighi della pubblica amministrazione.". ${ }^{5}$

Si somos consecuentes con la circunstancia de que la buena administración se encuentra en la esencia misma de todo el fenómeno administrativo, así como con la condición de principio general que ha de revestir la configuración jurídica de la buena administración, y con el rol que, por ser tal, ha de desempeñar en el ámbito jurídico-administrativo, no podemos menos que asumir que su contenido atañe tanto a la esfera de la organización, cuando a la del funcionamiento administrativo. Lo que significa que es este un principio que ha de aparecer informando el plano estructural de la Administración Pública (como aparato), y también a su esfera funcional, quedando proyectado su contenido hacia ambos espacios objetivos.

Por otro lado, siguiendo la orientación argumental que ahora nos mueve, no debe dejarse fuera de la vista el hecho de que, como hemos sostenido en un acápite precedente, la buena administración evoca la consideración de parámetros objetivos previamente fijados o determinados en función de ciertos fines, cuyo cumplimiento ha de señalar entonces la consideración positiva de dicho fenómeno en su concreción o realización material. Así como que ha de darse la buena administración cuando se han empleado bien los medios en la actuación administrativa y se ha llegado, por esa vía, al correcto cumplimiento de los fines a los que esos medios han de servir, todo ello dentro del marco jurídico existente, que ha de estar inspirado en valores y principios que garanticen y conduzcan a la plena realización del hombre social e individualmente considerado. De tal suerte, la buena administración como principio ha de tocar directamente tanto el orden del alcance o cumplimiento de determinados resultados, como de los medios para conseguir esos resultados.

95 CASSESE, Sabino, ob. cit., p. 7. 
En consonancia con planteamientos de ese tipo, no puede menos que asumirse que el principio de buena administración ha de comportar a la vez "principios de fondo y garantías procedimentales»; ${ }^{96}$ o principios y garantías que tienen que ver tanto con el plano formal o procedimental como con el plano sustantivo. ${ }^{97}$

Dentro de ese prisma, y relativo al contenido del principio de buena administración, reviste especial relevancia la relación entre la buena administración y el procedimiento administrativo, institución esta que en las últimas décadas ha cobrado un destacado valor e importancia teórico-práctica; en tanto han ido en aumento las preocupaciones sobre cómo se ejerce la función administrativa, y cómo se puede perfeccionar al procedimiento administrativo desde lo que es: el cauce jurídico de realización del funcionamiento administrativo, con todas las implicaciones que esa realización ha de significar para calificarse como tal. Mucho del contenido del principio de buena administración se vierte sobre el cauce procedimental del funcionamiento administrativo; y los principios, deberes y derechos que la buena administración revela, no vienen sino a convertirse en principios que rigen y conforman al procedimiento administrativo como institución de relevancia en el Derecho Administrativo, y en deberes y derechos concretos que encuentran su virtualidad dentro del mismo, como vía de producción de un actuación jurídico-administrativa que genera efectos sobre el o los destinatarios de dicha actuación. ${ }^{98}$

96 Delvolvé, Pierre, "Le droit à une bonne administration", p. 288, disponible en www.iias. sinica.edu.tw/cht/index.php.

97 Carrillo Donaire, Juan Antonio, ob. cit., p. 1141.

98 Como hace años puso de relieve Ponce SolÉ, a tenor del ordenamiento jurídico español: “El deber de buena administración es, pues, un aspecto de la función administrativa, que indica cómo debe ejercerse ésta. Cuando esta función administrativa se desarrolla mediante potestades, éstas implican la existencia de sujeción por parte de los administrados, como es conocido, pero también el sometimiento de quien ejerce la potestad al deber de buena administración. Deber que encuentra uno de sus mecanismos técnicos de articulación en la institución del procedimiento administrativo, que la Constitución reserva para el ejercicio del poder jurídico-administrativo, (...).". Previamente, Ponce Solé, había apuntado: “EI 
Como pieza de engranaje, el principio de buena administración se coloca como elemento de una mecánica funcional que debe conectarse a su vez, a nivel más abierto, con otros valores y principios que determinan y sustancian el actual universo jurídico-administrativo (iuspúblico, en general), operando como un sistema de fundamentación que aporta contenido y sentido al planteamiento y funcionalidad de dicho universo. En esa conexión debe destacarse el vínculo con valores y principios que deben estar en los cimientos mismos de la maquinaria jurídico-administrativa, como pueden ser - entre otros -: la democracia, la dignidad humana, la libertad (en sus diversos ámbitos de expresión), la solidaridad, la igualdad, la vocación social, el principio democrático, el de la división de funciones, el de juridicidad, el de solidaridad, el de la seguridad jurídica, el de la prevalencia del interés general, el de tutela judicial efectiva, el de igualdad o no discriminación, el de prohibición o interdicción de la arbitrariedad para los poderes públicos.

Como puede verse, hemos destacado aquí un nivel más abierto para apreciar la imbricación del principio de buena administración con otros grandes valores y principios que informan el ordenamiento jurídico-administrativo, de los que incluso la buena administración viene a ser una consecuencia necesaria y también una vía para realizarlos (como puede entenderse de principios como el democrático, la juridicidad, el de Estado de Derecho, etc.).

\footnotetext{
procedimiento administrativo se configura, así, como uno de los instrumentos jurídicos posibilitadores del cumplimiento del deber de buena administración, como un factor, por tanto, de potenciación de las posibilidades de obtención de decisiones administrativas de calidad y, en definitiva, como un elemento de legitimación de las Administraciones Públicas.". PonCE Solé, Juli, ob. cit., pp. 197 y 127.
} 